\title{
Fiscal Rules and the Intergenerational Welfare Effects of Public Investment
}

\author{
Pedro R. D. Bom*
}

October 2016

\begin{abstract}
A common argument against balanced-budget fiscal rules has it that the costs of durable public capital fall entirely on current generations while its benefits also accrue to future generations. This paper proposes an additional reason why balancedbudget rules imply uneven welfare effects of public investment across generations. Using an overlapping generations model of a small open economy, I show that, when subject to a balanced-budget constraint, public investment causes a negative financial wealth effect on the welfare of current generations. Numerical simulations of the model show that this negative effect more than offsets the productivity gains of higher public investment spending, leaving current generations worse-off. A golden rule exempting net public investment from the balanced-budget requirement overturns this effect and allows for welfare gains to both current and future generations.
\end{abstract}

JEL codes: E62, F41, H54

Keywords: balanced-budget rule, golden rule, intergenerational welfare, public investment, public capital

${ }^{*}$ Deusto Business School, University of Deusto. Address: Hermanos Aguirre Kalea 2, 48014 Bilbao, Spain. Tel.: +34 944139 290. E-mail: pedro.bom@deusto.es. 


\section{Introduction}

The merits and perils of balanced-budget fiscal rules have long been discussed among academics and policymakers. The usual economic argument for strict budgetary rules lies in a deficit bias that supposedly plagues democratically-elected governments. The debate resurged in the aftermath of the recent global financial and economic crisis. To cope with large fiscal imbalances, many countries adopted new (or strengthened existing) fiscal policy rules (see Schaechter et al., 2012). In the European Union, for instance, member states signed a Fiscal Compact in 2012 stipulating that a structural deficit limit of $0.5 \%$ be adopted in national legislations as of 2013 . Fiscal discipline is not the only fiscal challenge to developed economies, however. According to the IMF (2014), public capitalto-GDP ratios in these countries have decreased by about five percentage points since the 1970s. The OECD (2012) too has warned that a large and increasing 'infrastructure gap' is likely to curtail long-run growth unless governments substantially increase the share of GDP devoted to public infrastructure spending.

Balanced-budget rules are often criticized for not distinguishing between current spending and capital expenditures. Whereas the benefits of current spending accrue to current generations, government investment on durable capital also provides benefits to future generations. By imposing the costs of durable public capital goods entirely on current generations, balanced-budget rules not only violate the principle of intergenerational equity but also compromise economic efficiency. Indeed, Bassetto and Sargent (2006) show that current generations would not support the optimal provision of public capital through voting if the entire tax burden implied by the additional public capital expenditures falls on themselves. In this paper, I explore an additional channel whereby balanced-budget rules give rise to very uneven welfare effects of public investment across generations. I argue that a permanent efficiency-enhancing increase in public investment may cause a negative financial wealth effect on current generations by lowering the market value of firms, if the government satisfies a balanced-budget constraint by varying labor income taxes. I show that this negative welfare effect more than offsets the productivity gains from a permanent public investment impulse, leaving current generations worse-off.

I study the intergenerational welfare effects of public investment using an overlapping generations model of a small open economy facing a perfectly-elastic supply of foreign capital at the exogenously-given interest rate. The government levies a proportional tax on labor income and invests on public capital, which provides productive services to private firms as a pure public good. As a baseline fiscal scenario, I assume the government 
is constrained by a balanced-budget rule and varies the labor income tax endogenously to match its outlays, as in Schmitt-Grohé and Uribe (1997) and Xue and Yip (2015). On the household side, I assume a Blanchard (1985)-Yaari (1965) structure of overlapping and disconnected generations of finitely-lived households facing a constant probability of death. Despite oversimplifying mortality risk and ruling out life-cycle behavior, this assumption allows for financial wealth heterogeneity across cohorts, while keeping the model analytically tractable. Importantly, I endogenize labor supply along the lines of Bom and Ligthart (2014a). As is common in the literature on small open economies facing exogenously-given interest rates, I assume convex capital adjustments costs to private capital. This assumption gives rise to a responsive Tobin's $q$-i.e., the market value of installed private capital relative to its replacement cost - which temporarily absorbs any shocks to the marginal product of private capital.

I log-linearize the model around its steady state and derive the analytical impulse response functions to a permanent public investment impulse for the relevant macroeconomic variables. The cohort-specific welfare impact is then expressed as function of the macroeconomic responses, distinguishing between two main welfare effects: a human wealth effect reflecting future developments in after-tax wages, and a financial wealth effect measuring the impact of public investment on the market value of domesticallyowned financial assets. I calibrate the model to an average economy in the euro area, which yields an initial steady state with inefficiently low public capital, and then simulate the macroeconomic and intergenerational welfare effects of an efficiency-enhancing permanent impulse to public investment.

The results show that a balanced-budget rule implies rather uneven welfare effects of public investment across generations. The standard argument, represented by the human wealth effect, plays a role: the balanced-budget rule disproportionately benefits future generations by providing sizable long-run productivity gains while requiring larger tax rate increases in the short run. Current generations still enjoy welfare gains from the human wealth change, but rather small. But public investment also triggers a negative financial wealth effect on current generations. Because the balanced-budget constraint implies large short-run increases in distortionary labor tax rates, labor employment is strongly reduced on impact, which reduces private capital productivity and, thus, Tobin's $q$. This effect harms the welfare of current generations, especially older ones, by decreasing the firms' stock market value. In the baseline calibration, the negative financial effect outweighs the positive human wealth effect. 
I then study the effects of exempting net public investment from the balanced-budget constraint, as proposed by Blanchard and Giavazzi (2004). This so-called 'golden rule' allows net public capital spending to be financed with debt but maintains the balancedbudget constraint on all other components of spending. This rule has been implemented in many countries and is still in place in most U.S. states. The golden rule changes the intergenerational welfare effects in two ways. First, it evens out the wealth effect across generations by reversing the timing of taxes - i.e., lower increases in the short run compensated by larger increases in the long run-which smooths out the time profile of after-tax wages. Second, and most important, the golden rule overturns the negative financial wealth effect. Because tax rates increase by less in the short run, the impact employment contraction is reduced, which prevents the market value of firms from falling. Taken together, the two effects imply that the golden rule allows for welfare gains from public investment to both current and future generations.

This paper is closely related to the literature on the real dynamics effects of productive government spending, such as Baxter and King (1993), Turnovsky and Fisher (1995), and Leeper, Walker, and Yang (2010). However, these studies employ the standard infinitelylived representative agent framework and do not study the welfare implications of public investment. Heijdra and Meijdam (2002) do study the intergenerational impact of public investment, but assume exogenous labor supply and lump-sum taxes. Bom and Ligthart (2014a) endogenize labor supply and consider distortionary labor income taxes, but do not study welfare.

A second strand of related literature compares the relative economic and welfare performance of balanced budget and golden rules (among others). Minea and Villieu (2009) find, using an endogenous growth model, that balanced-budget rules maximize long-run growth while a golden rule may lead to higher welfare. Groneck (2010), in contrast, concludes that golden rule increases long-run growth but not necessarily welfare. Creel, Hubert, and Saraceno (2013) build a small-scale New-Keynesian model with no explicit production sector to show that a golden rule implies lower output losses from a debt stabilization policy. Menguy (2015) also uses a New-Keynesian to find that a golden rule can enhance welfare in countries within a monetary union, especially if tax rates are high and public investment is efficient. The present paper contributes to this literature by focusing on the implications of balanced-budget and golden rules for the joint dynamics of factor markets as a response to a public investment shock. ${ }^{1}$

\footnotetext{
${ }^{1}$ Schmitt-Grohé and Uribe (1997) initiated another, less directly related, strand of literature suggesting that balanced-budget rules may imply belief-driven macroeconomic fluctuations. Guo and Harrison
} 


\section{The Model}

This section describes the elements of the macroeconomic model. Detailed mathematical derivations are provided in the Technical Appendix to this paper (Bom, 2016).

\section{$2.1 \quad$ Households}

The economy is inhabited by infinitely many disconnected generations of households, indexed by birth date $v$, who derive instantaneous utility according to

$$
U(v, t)=C(v, t)^{\varepsilon_{C}}[1-L(v, t)]^{1-\varepsilon_{C}}, \quad 0 \geq \varepsilon_{C} \geq 1
$$

where $C(v, t)$ and $L(v, t)$ denote goods consumption and labor. Time is normalized to one, so that $1-L(v, t)$ denotes leisure. Note that this non-separable preference specification imposes a unitary elasticity of substitution between consumption and leisure.

I employ the standard Yaari (1965)-Blanchard (1985) formulation of finite lives, where the instantaneous probability of death, $\beta$, is assumed to be constant-i.e., households are perpetually young. Individuals insure against the mortality risk via a perfect annuity market. At $t \geq v$, therefore, individual households choose consumption and labor to maximize

$$
\Lambda(v, t)=\int_{t}^{\infty} \ln U(v, \tau) e^{(\alpha+\beta)(t-\tau)} d \tau
$$

subject to the household (flow) budget constraint

$$
\dot{A}(v, t)=(r+\beta) A(v, t)+\bar{w}(t) L(v, t)-C(v, t),
$$

and the transversality condition $\lim _{\tau \rightarrow \infty} A(v, \tau) e^{(r+\beta)(t-\tau)}=0$. In the objective function (2), $\alpha$ denotes the pure rate of time preference; given the mortality risk parameterized by $\beta$, households discount the future at rate $\alpha+\beta$. In the budget constraint $(3), A(v, t)$ is the individual stock of financial assets, $\bar{w}(t) \equiv w(t)\left[1-t_{L}(t)\right]$ denotes the after-tax wage rate $\left(w(t)\right.$ and $t_{L}(t)$ being the before-tax wage and the tax rate on labor income), and $r$ is the exogenously-given world rate of interest. Dots denote time derivatives (e.g., $\dot{A}(v, t) \equiv d A(v, t) / d t)$. Households are born and pass away at the same rate, $\beta$, implying a constant population size that I normalize to one. Notice the additional term $\beta$ in the effective rate of return on financial wealth, $r+\beta$, which reflects the annuity return.

(2008) reexamine this result in light of utility and production externalities of public expenditures. 
The household's problem is more conveniently solved by first defining

$$
X(v, t) \equiv \bar{w}(t)[1-L(v, t)]+C(v, t)=P(t) U(v, t)
$$

which I refer to as 'full consumption'-i.e., the combined market value of goods consumption and leisure. The variable $P(t)$ denotes a 'true' price index (derived below). The household's first-order conditions then consist of an intertemporal Euler equation for full consumption:

$$
\frac{\dot{X}(v, t)}{X(v, t)}=r-\alpha,
$$

and two intratemporal equations determining the (fixed) split of full consumption between goods consumption and leisure:

$$
\begin{aligned}
C(v, t) & =\varepsilon_{C} X(v, t), \\
\bar{w}(t)[1-L(v, t)] & =\left(1-\varepsilon_{C}\right) X(v, t) .
\end{aligned}
$$

Equations (6)-(7) can now be substituted in (1) to find the price index

$$
P(t)=\left(\frac{1}{\varepsilon_{C}}\right)^{\varepsilon_{C}}\left(\frac{\bar{w}(t)}{1-\varepsilon_{C}}\right)^{1-\varepsilon_{C}} .
$$

Despite its simplistic description of mortality, the perpetual youth assumption has two advantages. First, it is analytically convenient, as it admits a simple closed-form solution for the level of consumption that allows aggregation across individuals (see below). Indeed, integrating the budget constraint (3) while using the Euler equation (5) and imposing the transversality condition yields

$$
X(v, t)=(\alpha+\beta)[A(v, t)+H(t)]
$$

This individual consumption function expresses full consumption as a constant fraction of total individual wealth, consisting of a financial wealth component, $A(v, t)$, and a human wealth component, $H(t) \equiv \int_{t}^{\infty} \bar{w}(\tau) e^{(r+\beta)(t-\tau)} d \tau$. Since the wage rate is ageindependent, only financial wealth depends on the individual's cohort. Hence, because of the the perpetual youth assumption, consumption varies across cohorts only inasmuch as financial wealth does. This is a second advantage, for it allows us to focus on the financial wealth component as a key channel through which public investment affects individual 
welfare.

Variables at the individual level need to be aggregated across cohorts. At time $t$, a cohort born at time $v \leq t$ represents a fraction $\beta e^{\beta(v-t)}$ of total population (of size one). Aggregating a generic individual quantity $x(v, t)$ thus amounts to integrating $x(v, t)$ across all living cohorts with their sizes taken into account:

$$
x(t)=\int_{-\infty}^{t} x(v, t) \beta e^{\beta(v-t)} d v .
$$

It can be readily shown that the first-order conditions (6) and (7) yield analogous expressions in the aggregate (i.e., without the index $v$ ). The aggregate flow budget constraint is obtained by first aggregating (3) and then taking its time derivative. This yields

$$
\dot{A}(t)=r A(t)+\bar{w}(t)-X(t) .
$$

Notice that $\beta$ drops from the effective rate of return, since it merely represents intergenerational transfers of financial assets that wash out in the aggregate. Integrating individual Euler equation (5) along the same lines gives

$$
\frac{\dot{X}(t)}{X(t)}=r-\alpha-\frac{\beta(\alpha+\beta) A(t)}{X(t)}
$$

which is the familiar Keynes-Ramsey rule augmented with a 'generational turnover effect' (represented by the last term). In a steady state with $\dot{X}(t)=0$, therefore, positive aggregate net worth (i.e., $A(t)>0$ ) implies $r>\alpha$. From (5) and (6), it then follows that consumption, despite being constant at the aggregate level, increases over time at the individual level. To resolve this apparent discrepancy, note that the absence of a bequest motive and $r>\alpha$ imply rising individual profiles of financial assets over the course of life. Hence, older cohorts are financially wealthier and consume more than younger ones.

\section{$2.2 \quad$ Firms}

Perfectly competitive firms produce homogeneous output, $Y(t)$, using private capital, $K_{G}(t)$, and labor, $L(t)$, taking as given the stock of public capital, $K(t)$. Public capital is modeled as a pure public good, providing productive services to private firms free of charge and without congestion. The production technology is Cobb-Douglas, implying 
that public capital augments private inputs in a Hicks-neutral fashion:

$$
Y(t)=K(t)^{\varepsilon_{Y}} L(t)^{1-\varepsilon_{Y}} K_{G}(t)^{\eta}
$$

where $\varepsilon_{Y} \in(0,1)$ and $\eta \geq 0$ denote the output elasticities of private and public capital. The representative firm maximizes the present value of its cash flow:

$$
V(t) \equiv \int_{t}^{\infty}[Y(\tau)-w(\tau) L(\tau)-I(\tau)] e^{r(t-\tau)} d \tau
$$

subject to the capital accumulation constraint

$$
\dot{K}(t)=\left[\Phi\left(\frac{I(t)}{K(t)}\right)-\delta\right] K(t)
$$

where $\delta \in(0,1)$ denotes the depreciation rate of private capital and $\Phi(x)$ is a strictly concave accumulation function (i.e., $\Phi^{\prime}(x)>0$ and $\Phi^{\prime \prime}(x)<0$ ) reflecting capital adjustment costs, which are zero at the origin (i.e., $\Phi^{\prime}(0)=1$ ) but increase with $x$. The presence of capital adjustment costs requires transitory fluctuations in Tobin's $q$-i.e., the market value of installed capital relative to its replacement cost - to absorb changes in the marginal productivity of private capital.

The firm's optimization problem gives rise to three first-order conditions, one of which governs the dynamics of Tobin's $q$ :

$$
\dot{q}(t)=-q(t)\left[\Phi\left(\frac{I(t)}{K(t)}\right)-\frac{I(t)}{K(t)} \Phi^{\prime}\left(\frac{I(t)}{K(t)}\right)-(r+\delta)\right]-\varepsilon_{Y} \frac{Y(t)}{K(t)} .
$$

Note that this equation boils down to $\varepsilon_{Y} \frac{Y(t)}{K(t)}=r+\delta$ (i.e., the standard condition equating the marginal productivity to the marginal cost of capital) in a model without adjustment costs (i.e., $\Phi(x)=x$ ). The other two first-order conditions are static equations determining labor and investment demand:

$$
\begin{aligned}
w(t) & =\left(1-\varepsilon_{Y}\right) \frac{Y(t)}{L(t)}, \\
1 & =q(t) \Phi^{\prime}\left(\frac{I(t)}{K(t)}\right) .
\end{aligned}
$$

Condition (16) equates the gross wage rate to the marginal productivity of labor, whereas (17) implicitly determines the optimal level of investment given the capital stock and Tobin's $q$. 


\subsection{Government and Fiscal Rules}

The government spends on productive public investment, $I_{G}(t)$, and unproductive public consumption goods, $C_{G}(t)$. Like private capital, public capital is subject to adjustment costs. Denoting the depreciation rate of public capital by $\delta_{G}$, public capital accumulates according to

$$
\dot{K}_{G}(t)=\left[\Phi_{G}\left(\frac{I_{G}(t)}{K_{G}(t)}\right)-\delta_{G}\right] K_{G}(t)
$$

where $\Phi_{G}(x)$ is a strictly concave accumulation function with no marginal adjustment costs at zero gross investment (i.e., $\Phi_{G}^{\prime}(x)>0, \Phi_{G}^{\prime}(0)=1$, and $\left.\Phi_{G}^{\prime \prime}(x)<0\right)$.

To finance its expenditure flow, the government levies a proportional tax on labor income, $t_{L}(t)$, and issues government bonds. The government's flow budget constraint is

$$
\dot{B}(t)=r B(t)+I_{G}(t)+C_{G}(t)-t_{L}(t) w(t) L(t),
$$

where $B(t)$ denotes the stock of government debt outstanding at time $t$. I consider two alternative fiscal rules: (i) a balanced-budget rule, and (ii) a golden rule for net investment. The government fully commits to the fiscal rule in place, which rules out risk of debt default.

\subsubsection{Balanced-Budget Rule}

The baseline fiscal scenario is a balanced-budget fiscal rule stipulating that all government spending be financed through tax revenues. By precluding debt-financing of public investment, the balanced-budget rule imposes $\dot{B}(t)=0$ in (19). Hence, the government must vary the tax rate according to

$$
t_{L}(t)=\frac{r B(t)+I_{G}(t)+C_{G}(t)}{w(t) L(t)}
$$

which ensures that, given the evolution of the the tax base, $w(t) L(t)$, sufficient tax revenues are raised so as to service public debt and finance government consumption and investment expenditures.

\subsubsection{Golden Rule}

The alternative fiscal scenario is a golden rule for net investment, as advocated by Blanchard and Giavazzi (2004) to improve the Stability and Growth Pact in the European 
Union. The golden rule exempts net public capital spending from the balanced-budget constraint, thus requiring that public capital adjustment and depreciation costs be imputed to the ordinary (balanced) budget. Hence, changes in the stock of public debt mirror changes in the stock of public capital. Imposing $\dot{B}(t)=\dot{K}_{G}(t)$ and combining (19) and (18) gives the labor tax rate implied by the golden rule:

$$
t_{L}(t)=\frac{r B(t)+I_{G}(t)+C_{G}(t)-\left[\Phi\left(\frac{I_{G}(t)}{K_{G}(t)}\right)-\delta_{G}\right] K_{G}(t)}{w(t) L(t)},
$$

where the last (negative) term in the numerator reflects the exemption of the net public capital change from the balanced-budget constraint.

\subsection{Market Equilibrium}

The model abstracts from any nominal or real rigidities apart from capital adjustment costs. The labor market and the goods market thus clear at each instant of time. Denoting next exports by $Z(t)$, equilibrium in the goods market amounts to

$$
Y(t)=C(t)+I(t)+C_{G}(t)+I_{G}(t)+Z(t)
$$

Financial assets are perfect substitutes. Hence, financial portfolio equilibrium implies

$$
A(t)=q(t) K(t)+B(t)+F(t)
$$

where $q(t) K(t)$ measures the stock market value of firms and $F(t)$ denotes the stock of net foreign assets, which evolves according to $\dot{F}(t)=r F(t)+Z(t)$.

\section{Model Solution}

This section describes the solution of the model. Section 3.1 solves for the macroeconomic dynamics of a public investment shock. Section 3.2 develops a graphical framework to depict these dynamic effects. Section 3.3 derives the intergenerational welfare effects of public investment from its macroeconomic impact. 


\subsection{Comparative Dynamics}

I log-linearize the model around a steady state with zero net foreign assets (i.e., $F=0$ ) and zero net public assets (i.e., $B=K_{G}$ ). In general, the change of a variable $x(t)$ relative to its steady-state value $x$ is denoted by $\tilde{x}(t) \equiv d x(t) / x$. The exceptions are the asset-like variables (i.e., $H(t), F(t), B(t)$, and $A(t)$ ), which are defined as $\tilde{x}(t) \equiv r d x(t) / Y$; and the labor tax rate, which is defined as $\tilde{t}_{L}(t) \equiv d t_{L}(t) /\left(1-t_{L}\right)$. Appendix A.1 describes the log-linearized equations of the model.

Solving the log-linearized model amounts to finding the impulse response functions to the public investment shock. I solve the model analytically in three steps. First, I set up a static system describing the labor market equilibrium (see Appendix A.2.1). This system allows us to find the quasi-reduced form solutions of $\tilde{Y}(t), \tilde{L}(t)$, and $\tilde{w}(t)$, conditional on the state variables of the model. Next, I arrange the state variables in the state vector $\tilde{\mathbf{S}}(t) \equiv[\tilde{K}(t) \tilde{q}(t) \tilde{X}(t) \tilde{A}(t)]^{\prime}$ and set up a linear dynamic system of the form

$$
\dot{\tilde{\mathbf{S}}}(t)=\Delta \tilde{\mathbf{S}}(t)+\Gamma(t)
$$

where $\boldsymbol{\Delta}$ is a $4 \times 4$ Jacobian matrix and $\boldsymbol{\Gamma}(t)$ is a $4 \times 1$ vector containing the public investment shock (see Appendix A.2.2). Finally, after solving for the state variables in the dynamic system (reported in Appendix A.2.4) and recovering $\tilde{Y}(t), \tilde{L}(t)$, and $\tilde{w}(t)$ from the static system, I solve for remaining variables (i.e., $\tilde{C}(t), \tilde{F}(t), \tilde{P}(t), \tilde{\bar{w}}(t)$, and $\left.\tilde{t}_{L}(t)\right)$ using equations (A.10)-(A.14).

The stability properties of the model depend on the characteristic roots of $\boldsymbol{\Delta}$. Its trace and determinant are both positive for not too large elasticities of labor supply (see Appendix A.2.2), indicating either four positive or two positive and two negative roots. For plausible parameter values, the model exhibits two positive roots and two negative roots, implying a unique, saddle-path stable equilibrium (see Section 4.1). As in Bom and Ligthart (2014a), the roots may be complex for moderately 'large' labor supply elasticities, in which case the impulse responses are cyclical. Two other cases are worth mentioning. First, a zero root obtains in the special case of infinitely-lived households (i.e., $\beta=0$, which requires $r=\alpha$ ), giving rise to a hysteretic steady state. Second, exogenous labor supply allows for a recursive dynamic structure, where the subsystem $\tilde{K}(t)-\tilde{q}(t)$ can be solved independently of the subsystem $\tilde{X}(t)-\tilde{A}(t)$. 


\subsection{Graphical Framework}

Figure 1 provides a graphical illustration of the dynamics of a public investment shock using a system of three interconnected panels, representing the capital and labor markets and the household's consumption-saving subsystem. The capital market and the consumption-saving subsystem correspond to subsystems $\tilde{K}(t)-\tilde{q}(t)$ and $\tilde{X}(t)-\tilde{A}(t)$ in $(23)$, which are connected by the dynamics of labor employment. In this section I describe the main elements of the graphical framework and the long-run forces triggered by public investment. The impact and transitional dynamics (depicted by dotted arrows) are discussed in Section 4.2, in conjunction with the numerical impulse response functions. ${ }^{2}$

Panel (a) represents the labor market in the $w$ - $L$ space, consisting of an aggregate supply curve $\left(L_{s}\right)$ and an aggregate demand curve $\left(L_{d}\right)$. The former plots equation $(7)$ and slopes upwards, given full consumption. The latter represents equation (16) and is negatively sloped. A permanent increase in public investment affects the labor market by improving the marginal product of labor, which shifts out the $L_{d}$ curve. On the other hand, tax-financing public investment distorts households' labor supply decisions, which shifts the $L_{s}$ curve leftwards. Public investment also affects the labor market indirectly through wealth effects on labor supply (reflected in variations in full consumption). A positive wealth effect (increase in $X$ ) shifts the $L_{s}$ curve to the left, and vice-versa.

Panel (b) depicts the capital market, whose dynamics are governed by the steadystate conditions $\dot{K}(t)=0$ and $\dot{q}(t)=0$. Imposing these conditions in (14) and (15) gives rise to:

$$
\begin{array}{ll}
q=\frac{1}{\Phi^{\prime}\left(\Phi^{-1}(\delta)\right)}, & (\dot{K}=0) \\
q=\frac{1}{r}\left(\varepsilon_{Y} \frac{Y}{K}-\frac{I}{K}\right), & (\dot{q}=0)
\end{array}
$$

where the former is horizontal at the unique steady-state value of Tobin's $q$ and the latter slopes downwards in the $q-K$ space. A permanent impulse to public investment shifts the $\dot{q}=0$ to the right by improving the marginal product of private capital.

Finally, Panel (c) depicts the dynamics of full consumption and financial assets, which

\footnotetext{
${ }^{2}$ The four-dimensional nature of system (23) precludes a rigorous graphical analysis of the dynamics of the model using standard two-dimensional phase diagrams. The graphical framework is used here merely for illustration of the impulse response functions.
} 
are determined by the steady-state conditions $\dot{X}(t)=0$ in (11) and $\dot{A}(t)=0$ in (10):

$$
\begin{aligned}
& X=\frac{\beta(\alpha+\beta)}{r-\alpha} A, \\
& X=r A+w\left(1-t_{L}\right) .
\end{aligned}
$$

Both the $\dot{X}=0$ and the $\dot{A}=0$ lines slope upwards in the $X$-A space. Public investment affects only the $\dot{A}=0$ curve, shifting it up via permanently higher gross wages, and down via higher tax rates. The net effect is positive if after-tax wages increase, and vice-versa.

\subsection{Intergenerational Welfare}

As detailed in the Technical Appendix (see Bom, 2016), the lifetime utility change of an household of cohort $v \leq t$ can be written as a function of the changes in individual full consumption and in the price level (relative to steady-state values) as follows:

$$
d \Lambda(v, t)=\frac{\tilde{X}(v, t)}{\alpha+\beta}-\int_{t}^{\infty} \tilde{P}(\tau) e^{(\alpha+\beta)(t-\tau)} d \tau
$$

In evaluating (24) for a particular cohort, I distinguish between generations that are alive at the time of the public investment shock (for which $v \leq 0$ ) and generations yet to be born (for which $v>0$ ). Welfare of current generations is evaluated at the time of the shock (i.e., $t=0$ ), whereas welfare of future generations is evaluated at birth (i.e., $t=v$ ).

Writing (9) for $t=0$ gives full consumption of an household of cohort $v<0$ as a constant fraction of total wealth:

$$
X(v, 0)=(\alpha+\beta)[H(0)+A(v, 0)] .
$$

This equation can be log-linearized and expressed, in a few steps, as

$$
\tilde{X}(v, 0)=\frac{e^{(r-\alpha) v}}{\omega_{H}} \tilde{H}(0)+\frac{1-e^{(r-\alpha) v}}{\omega_{A}} \tilde{A}(0)
$$

where $\omega_{H} \equiv r H / Y$ and $\omega_{A} \equiv r A / Y$ are steady-state shares. Expression (26) writes the relative change in individual full consumption as a linear combination of relative changes in human wealth, $\tilde{H}(0)$, and financial wealth, $\tilde{A}(0)$, where the weights depend on the individual's age, $v$. For very old individuals (large negative $v$ ), the weight of $\tilde{H}(0)$ approaches zero, whereas the weight of $\tilde{A}(0)$ approaches $1 / \omega_{A}$. Full consumption of recently-born individuals (small negative $v$ ), in contrast, is more sensitive to changes in 
human wealth than to changes in financial wealth; as $v \rightarrow 0^{-}$, the weights of $\tilde{H}(0)$ and $\tilde{A}(0)$ approach $1 / \omega_{H}$ and zero, respectively.

The response of full consumption to changes in financial wealth increases with age because, given the absence of bequests, households start off with no financial wealth and accumulate savings over the course of their lives. Of course, this is also the reason why human wealth matters more for young cohorts. It would be reasonable to assume that human wealth matters less for older individuals also because of their shorter expected lifetimes. This life-cycle channel is inoperative in this model, however, since households are assumed to be perpetually young. The model may thus understate the importance of financial wealth for older individuals and the importance of human wealth for younger individuals.

Using (26) in (24), the welfare change at $t=0$ of a currently-living individual household of cohort $v \leq 0$ can be written as

$$
d \Lambda(v, 0)=\frac{e^{(r-\alpha) v}}{\omega_{H}(\alpha+\beta)} \tilde{H}(0)+\frac{1-e^{(r-\alpha) v}}{\omega_{A}(\alpha+\beta)} \tilde{A}(0)-\int_{0}^{\infty} \tilde{P}(\tau) e^{(\alpha+\beta)(t-\tau)} d \tau
$$

The welfare change of existing generations consists of three components. The first two terms on the right-hand side of (27) depend on the individual's age and correspond to the human wealth and financial wealth effects on welfare, respectively. The last term is independent of $v$ and measures the price level effect on welfare.

Because generations are disconnected and new individuals are born without financial wealth, full consumption of newborns consists of human wealth only. Hence, the relative change in full consumption at birth (i.e., at $t=v$ ) is simply given by $\tilde{X}(v, v)=\tilde{H}(v) / \omega_{H}$. Hence, the welfare change of future generation born at $t=v>0$ - evaluated at $v$-is

$$
d \Lambda(v, v)=\frac{\tilde{H}(v)}{\omega_{H}(\alpha+\beta)}-\int_{v}^{\infty} \tilde{P}(\tau) e^{(\alpha+\beta)(v-\tau)} d \tau
$$

In contrast to current generations, the welfare change of future generations does not contain a financial wealth effect. Naturally, the price level effect now depends on $v$.

\section{Numerical Simulations}

This section numerically simulates the macroeconomic and intergenerational welfare effects of public investment. Section 4.1 describes the calibration strategy. The simulation results concerning the the macroeconomic effects are discussed in Section 4.2, whereas 
those regarding intergenerational welfare are presented in Section 4.3. Section 4.4 studies the sensitivity of the welfare effects for alternative values of key model parameters. Section 4.5 summarizes the simulation results and discusses its limitations.

\subsection{Calibration}

Table 1 reports the benchmark parameter values used in the numerical simulations of the model. The model is calibrated as follows. In line with eurozone averages, I set the ratios of private consumption, government consumption, and public investment to $56 \%, 17 \%$, and $4 \%$ of GDP, respectively. Because the stock of net foreign assets is zero in the initial steady state, net exports are also zero. The implied private investment share of GDP is then 23\%. Following Bom and Ligthart (2014a), I specify the accumulation functions of both private and public capital as

$$
\Phi(x)=\Phi_{G}(x) \equiv \kappa[\ln (x+\kappa)-\ln \kappa], \quad \kappa>0,
$$

which is defined for $x>-\kappa$ and satisfies $\Phi^{\prime}(x)=\kappa(x+\kappa)^{-1}>0, \Phi^{\prime}(0)=1$, and $\Phi^{\prime \prime}(x)=-\kappa(x+\kappa)^{-2}<0$. I set $\kappa=0.532$, which implies capital adjustment costs of $0.2 \%$ of GDP in steady state. The depreciation rate of private capital is set at $10 \%$ and the world interest rate is fixed at 4\%. Using these values in equations (14) and (15) in steady state gives $\varepsilon_{Y}=0.331$, which implies capital and labor income shares of $1 / 3$ and $2 / 3$, respectively.

According to the IMF (2014), the average public capital-to-GDP ratio in advanced economies was about $58 \%$ in 2011 , close to the average public debt-to-GDP ratio at the beginning of the financial crisis. Hence, I set $K_{G} / Y=B / Y=0.58$. Equation (18) then implies a depreciation rate of $6.5 \%$ in steady state. Concerning the output elasticity of public capital, I pick Bom and Ligthart's (2014b) value of 0.080 as a benchmark. It is important to note that this value is twice as large as the initial public investment ratio. This difference implies that public investment is resource-augmenting in the long run, so that public investment and capital ratios are inefficiently low in the initial steady state. ${ }^{3}$ I check the sensitivity of the results to the alternative values of $\eta=0.05$ and $\eta=0.10$.

The leisure-labor ratio takes on the benchmark value of one. Given the utility specification (1), the leisure-labor ratio is equivalent to the Frisch-elasticity of labor supply,

\footnotetext{
${ }^{3}$ In fact, a permanent public investment shock of $10 \%$ would improve the welfare of an infinitelylived household, the target of a benevolent social planner without generational discounting (results not reported but available upon request).
} 
which is a key parameter in this model. Although unitary Frisch-elasticities are common in the literature (e.g, Drautzburg and Uhlig, 2015), the empirical magnitude of this parameter is far from consensual. I check the sensitivity of the results to the alternative values of $\omega_{L L}=0.5$ (more in line with empirical micro studies) and $\omega_{L L}=1.5$ (more in line with the macro literature). Given the values of government outlays, the unitary leisure-labor ratio pins down the tax rate at $t_{L}=0.349$ via (19) in steady state.

Given the values of the leisure-labor ratio, the tax rate, and the labor share of income, the aggregate versions of the households' first-order conditions (6) and (7) imply $\varepsilon_{C}=$ 0.562. The average household planning horizon is assumed to be 50 years, which is equivalent to setting $\beta=0.02$. The pure rate of time preference $\alpha=0.037$ then follows from the assumption of $F=0$ in (22) together with (11) in steady state. Finally, the benchmark parameter values imply saddle-path stability, with two unstable roots of 0.074 and 0.167 , and two stable roots of -0.030 and -0.127 .

\subsection{Dynamic Macroeconomic Effects}

Panel (a) of Figure 2 shows the macroeconomic responses to a $10 \%$ public investment impulse (i.e., $0.4 \%$ of GDP) for the balanced-budget rule (solid lines) and the golden rule (dashed lines). The time unit is an year. To build intuition into the macroeconomic forces at work, I complement the discussion of the numerical results with the graphical illustration in Figure 1 (described in Section 3.2).

Under a balanced-budget rule, the public investment impulse requires large tax rate increases in the short run. This is because the balanced-budget requirement induces a tax rate-tax base loop whereby higher tax rates reduce employment, which requires even higher taxes rates via a depressed tax base. The gross wage rate rises but, given the proportionally higher increase of the labor income tax rate, the net wage rate falls. Because private capital is initially pre-determined and later subject to adjustment costs, the impact drop in employment reduces its marginal productivity and, consequently, its market value (i.e., Tobin's q). Private investment is then discouraged, which subsequently reduces the stock of private capital. Importantly, the fall in Tobin's $q$ causes a negative financial wealth effect by decreasing the market value of firms' shares, which in turn decreases full consumption. The negative wealth effect raises labor supply to some extent, but this positive effect does not compensate the negative effect induced by the labor tax rate increase. In terms of Figure 1, these impact effects are triggered by the tax rateinduced leftward shift of the labor supply curve from its initial position $L_{s}$ to $L_{s}(0)^{B B}$ in 
Panel (a). Hence, the economy jumps on impact from $E$ to the momentary equilibrium $E_{0}^{B B}$ in the three panels.

The economy gradually recovers from the initial contraction as the stock of public capital builds up. Labor productivity and the gross wage rate increase in tandem with the accumulation of public capital. The resulting tax base expansion allows for lower tax rates, which stimulates labor supply and raises net wages. The labor market recovery is complete only about 12 years after the initial public investment shock. Labor employment and net wages further increase for another 25 years, after which they start a descending phase towards their steady-state values. In the long run, labor goes back to its initial level, but gross and net wages settle at higher levels. ${ }^{4}$ The long-run tax rate is also higher than before the shock - i.e., public capital does not entirely pay for itself-but much lower than in the first years after the shock. In Panel (a) of Figure 1, the transitional dynamics in the labor market are represented by the dotted BB path. Public capital accumulation shifts labor demand from $L_{d}$ towards $L_{d}(\infty)$, while the wealth effect on labor supply (discussed below) shifts labor supply from $L_{s}(0)^{B B}$ towards $L_{s}(\infty)$. The labor demand effect first dominates but ends up being eventually dominated by the labor supply effect.

As public capital expands and labor employment recovers, so does the marginal product of capital. After being depressed for about 3 years, Tobin's $q$ and private investment eventually rise above their pre-shock levels. In the long run, Tobin's $q$ returns to its initial level, while the private stock stabilizes at a higher level. The transitional increase in Tobin's $q$ and net wages induced by public capital accumulation generate a positive wealth effect, which steadily increases full consumption towards a higher long-run level. To accommodate higher consumption and private capital accumulation, the stock of domestic assets remains below its initial level for a long time, but eventually settles at a higher long-run value too. In Panel (b) of Figure 1, public capital accumulation shifts the $\dot{q}=0$ to the right, moving the economy from $E_{0}^{B B}$ to $E_{\infty}$ along the dynamic 'loop' represented by the dotted BB path. In Panel (c), a higher long-run stock of public capital pushes up the $\dot{A}=0$ line; the economy then transits from $E_{0}^{B B}$ to $E_{\infty}^{B B}$ following the BB path.

The golden rule roughly reverses the timing of taxes. The required increase in the labor income tax rate is much smaller on impact - about a fifth of the balanced-budget increase - but gradually increases over time to a higher long-run level. The resulting

\footnotetext{
${ }^{4}$ Because of the unitary elasticity of substitution between consumption and leisure in the utility function, the uncompensated (long-run) labor supply elasticity is exactly zero. Hence, labor employment is unresponsive to public investment in the long run.
} 
macroeconomic responses to the public investment shock differ in several aspects. First, and most obvious, the golden rule softens the size and duration of the short-run drop in net wages, at the cost of lowering net wages in the long run. Second, both the short-run employment contraction and the transitional expansion are less pronounced. Because of the smaller amplitude of tax rate changes, the GR path is less sinuous than the BB path in Panel (a) of Figure 1. The milder short-run labor contraction prevents Tobin's $q$ from falling, so that the financial wealth effect turns positive. In Panels (b), the economy jumps on impact to $E_{0}^{G R}$ and then transits towards $E_{\infty}$ following the GR path. ${ }^{5}$ Finally, the golden rule flattens the time profile of full consumption, increasing more in the short run and less in the long run than in the balanced-budget case. In Panel (c) of Figure 1, the economy moves from $E$ to $E_{0}^{G R}$ on impact, followed by a transitional movement towards $E_{\infty}^{G R}$.

\subsection{Intergenerational Welfare Effects}

Figure 3 shows the welfare effects of a permanent public investment impulse across generations, again distinguishing between the balanced-budget rule (solid lines) and the golden rule (dashed lines). Panel (a) plots the total welfare change at the time of the shock (i.e., at $t=0$ ) for generations alive at that point in time (i.e., $v \leq 0$ ), as given by (27). It shows both the total welfare change, $d \Lambda(v, 0)$, and its two key components, the human wealth effect and the financial wealth effect (first and second terms on the right-hand side). Panel (b) graphs the welfare change evaluated at birth (i.e., at $t=v$ ) for generations not yet born at the time of shock (i.e., $v>0$ ), as given by (28). It shows both the total welfare change, $d \Lambda(v, v)$, and the human wealth effect (first term on the right-hand side).

Under a balanced-budget rule, the welfare change of a permanent increase in public investment is negative for all living generations. Despite the short-run decline in net wages, the human wealth contribution to welfare is still positive for all depicted generations. But the negative financial wealth effect on welfare quantitatively dominates the small welfare gains from the human wealth increase. The strong impact drop in Tobin's $q$ decreases the stock market value of firms, especially affecting older generations, who own larger shares of firms' capital stocks. Generations born just before the shock are barely affected, since they own little financial wealth. Hence, all living generations loose from

\footnotetext{
${ }^{5}$ Note that the long-run effect on private capital is independent of the fiscal rule, since the rightward shift of the $\dot{q}=0$ is only determined by the public capital increase.
} 
the public investment shock, but older ones are more strongly affected.

Future generations, in contrast, enjoy welfare gains from positive human wealth effects (recall that future generations are not affected by the financial wealth effect). The welfare gains are modest for generations born soon after the shock, when net wages are still depressed, but quickly increase for generations born later. The highest welfare gains accrue to generations born about 40 years after the shock, when the labor tax is temporarily below its pre-shock rate and employment reaches its peak. Clearly, the balanced-budget rule distributes the welfare gains of public investment very unevenly, disproportionately benefiting future generations.

The golden rule changes the intergenerational welfare effects of public investment along both wealth effects, human and financial. First, by delaying higher tax rates to future generations, the golden rule smooths out the human wealth effect across current and future generations. Under the golden rule, therefore, the human wealth contribution to welfare is higher for current generations but lower for future generations. Second, by increasing Tobin's $q$ on impact, the golden rule reverses the sign of the financial wealth effect on welfare. Naturally, older living generations benefit more from public investment than younger ones under the golden rule, since they are financially wealthier. As a result, the total welfare change is positive for both current and future generations.

\subsection{Alternative $\omega_{L L}$ 's and $\eta$ 's}

Because it determines the extent to which labor taxes distort the labor market, the Frisch-elasticity of labor supply - determined by the leisure-labor ratio, $\omega_{L L}$-is a key parameter in this model. Figure 4 shows the effects of changing the value of this elasticity on the welfare effects of public investment on current generations. ${ }^{6}$ Panel (a) considers a smaller elasticity of $\omega_{L L}=0.5$. Qualitatively, the intergenerational profiles across living generations are very similar to those of Figure 3. The differences are mainly quantitative and rather small-because the labor market is distorted less, both fiscal rules give rise to slightly higher welfare profiles via the financial wealth effect. Conversely, as shown in Panel (b), the welfare profiles are slightly smaller for a higher labor supply elasticity of $\omega_{L L}=1.5$. It is worth noting that small elasticities can turn slightly negative the human wealth effect under a balanced-budget rule and the financial wealth effect under a golden rule.

Another key parameter in the model is the output elasticity of public capital, $\eta$,

\footnotetext{
${ }^{6}$ The results regarding future generations are available from the author upon request.
} 
which governs the size of public capital spillovers. Panel (a) of Figure 5 shows the intergenerational welfare profiles for a lower value of $\eta=0.05$. Compared to Figure 4 , the differences are both quantitative and qualitative. Public investment no longer improves the welfare of current generations, not even under a golden rule. Given its low spillover effect, public capital is initially abundant in this case. The human wealth effect is then negative for all current generations. Note that the financial wealth effect is higher for a lower $\eta$ in either fiscal rule. This seemingly counterintuitive result reflects the (negative) wealth effect on labor supply, which attenuates the negative employment response and, as a result, the impact drop in Tobin's $q$. Assuming $\eta=0.10$ as in Panel (b), on the contrary, gives rise to welfare gains to all living generations for both fiscal rules. Public capital is then so scarce that, in the balanced-budget rule, the human wealth effect is large enough to more than compensate the strongly negative financial wealth effect. In the golden rule case, the financial effect is virtually absent but the human wealth effect is even stronger.

\subsection{Discussion}

The baseline calibration of the model delivers the result that a permanent impulse to public investment, despite generating sizable welfare gains to future generations, harms the welfare of current generations if subject to a balanced-budget constraint. Although current generations also benefit from productivity gains in terms of higher long-run wages, the negative financial wealth effect is quantitatively stronger. Because the short-run employment contraction is key in generating this result, the financial wealth effect is naturally sensitive to the Frisch-elasticity of labor supply (governed by the leisure-labor ratio, $\left.\omega_{L L}\right)$. While totally dominating the welfare profile for values as high as 1.5 , however, the financial wealth effect still plays an important role for labor supply elasticities as low as 0.5. The financial wealth effect is also sensitive to the output elasticity of public capital, $\eta$, but much less so than the human wealth effect.

These results certainly depend on model features. First, the perpetual youth assumption rules out individual behavior over the life cycle. By overstating the relative importance of the human wealth effect for old individuals, this assumption may actually downplay the true importance of the financial wealth effect on welfare. Second, the assumption of no bequests and fully disconnected generations may understate the financial wealth effect on future generations and the human wealth effect on current generations. Third, the assumption that public capital does not provide direct utility understates the 
welfare effects on all generations, current and future. Incorporating these elements in the model would surely affect the intergenerational welfare profile of public investment. But they should not invalidate the main finding of this paper that higher public capital spending triggers a negative financial wealth effect on the welfare of current generations, which is eliminated if public investment is exempted from the balanced-budget requirement.

\section{Concluding Remarks}

This paper argues that a permanent public investment impulse can trigger a negative financial wealth effect on the welfare of current generations if the government balances its budget by means of labor income taxes. Because the productive effects of public capital spending take time to materialize, labor market distortions dominate in the short run, causing on impact a strong employment contraction that lowers the stock market value of existing firms. Calibrating the model with plausible parameter values delivers an initial steady state where public capital is underprovided. Permanently increasing public capital spending brings sizable long-run efficiency gains. But these gains are mostly reaped by future generations. The negative financial wealth effect can more than offset the welfare gains from higher productivity and wages, leaving current generations worse-off.

This result has important policy implications. In terms of intergenerational equity, to the extent that it affects only current generations the financial wealth effect exacerbates the uneven intergenerational distribution of welfare gains from public investment. In terms of economic efficiency, current generations may block political initiatives for higher, efficiency-enhancing public investment spending, preventing the optimal provision of public capital. I show that a golden rule that exempts net public investment from the balanced-budget constraint contributes to even out the intergenerational distribution of welfare gains - not only by smoothing out the time profile of labor income tax rates but also by reversing the sign of the financial wealth effect-leaving also current generations better-off from a public investment impulse.

The results in this paper can be extended in a number of ways. First, this paper assumes the government relies on labor income taxes to balance the budget, without considering other tax instruments or discussing optimal tax policy. Second, it would also be interesting to depart from full commitment and consider the possibility of debt default, which would add a risk premium component to the costs of public investment. Finally, the model could be embedded in a political economy framework to analyze voting 
incentives and the optimal provision of public capital. I intend to address same of these issues in future work. 
Figure 1: Macroeconomic Dynamics of a Public Investment Impulse Panel (a): Labor market

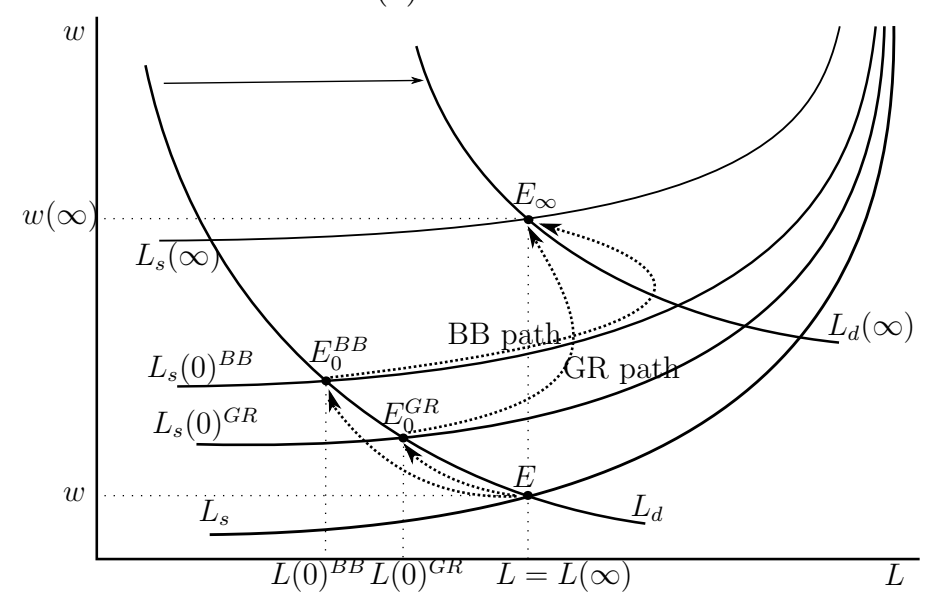

Panel (b): Capital market

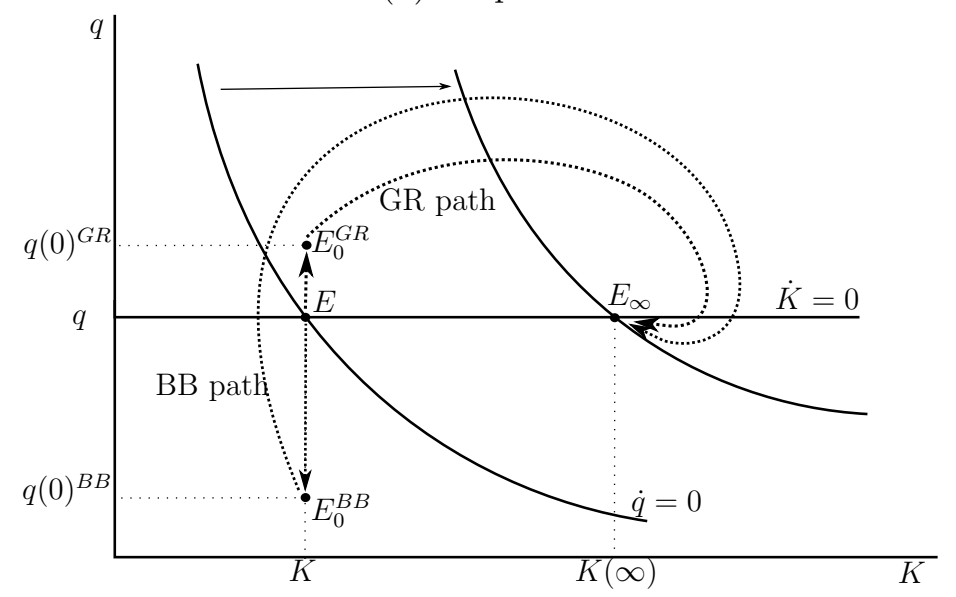

Panel (c): Consumption-saving subsystem

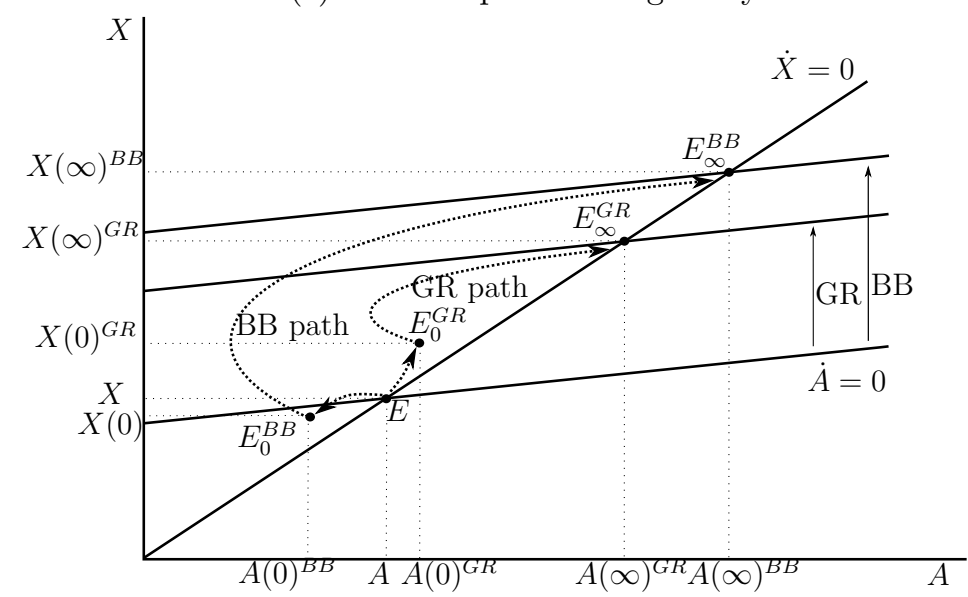


Figure 2: Macroeconomic Effects of a Permanent Impulse to Public Investment

Tax rate

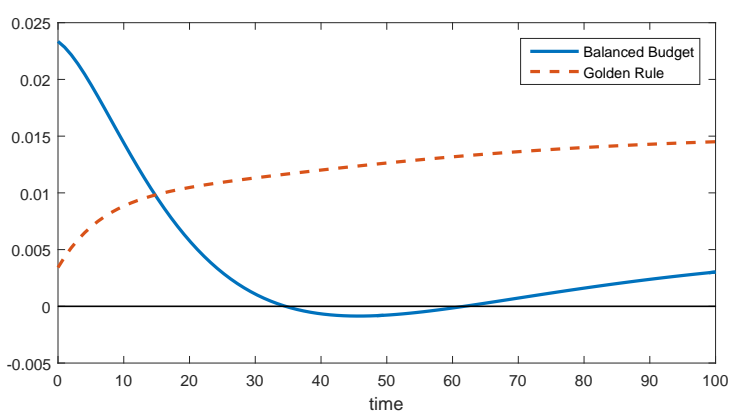

Gross wage rate

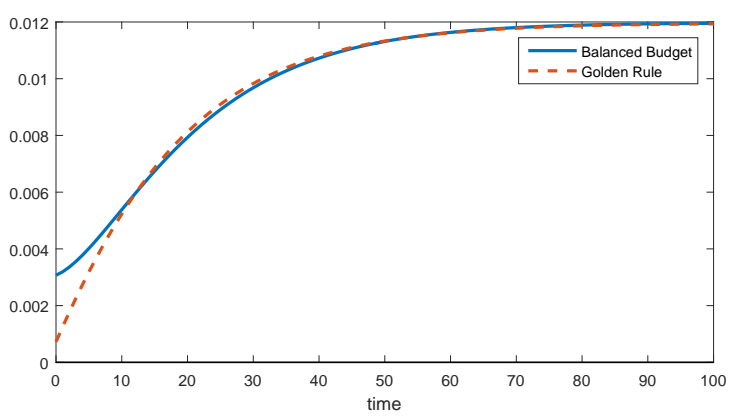

Tobin's $q$

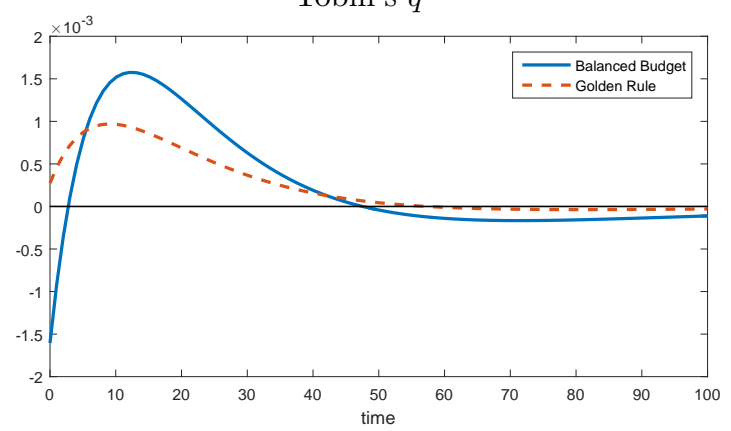

Financial assets

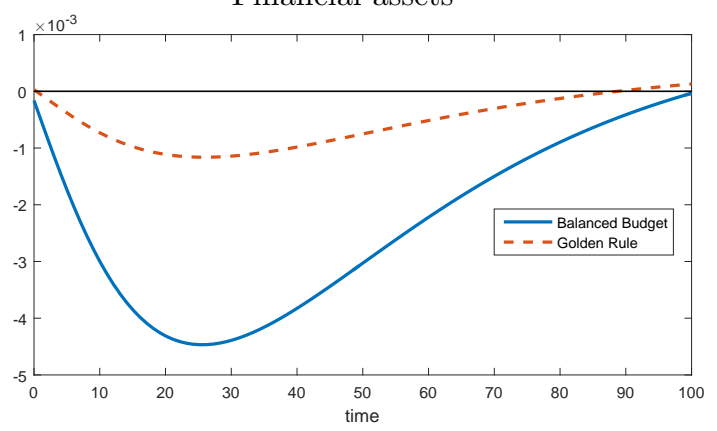

Labor

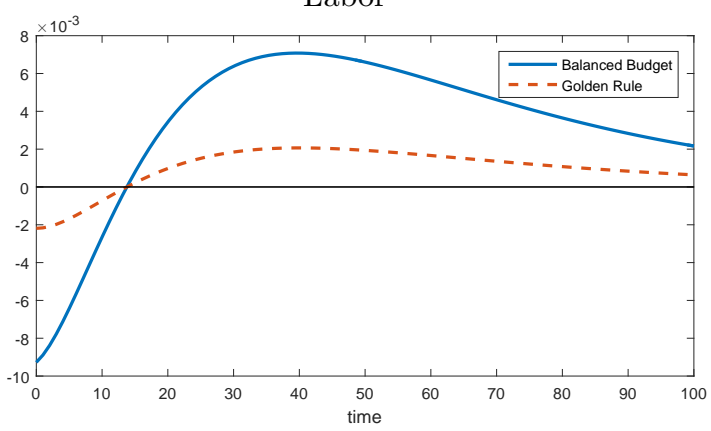

Net wage rate

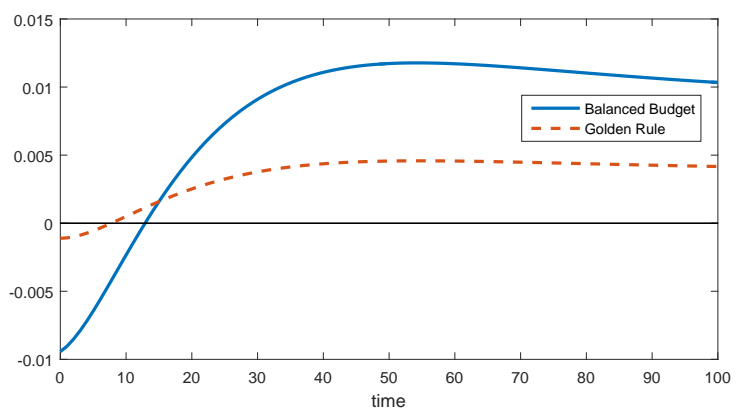

Private capital

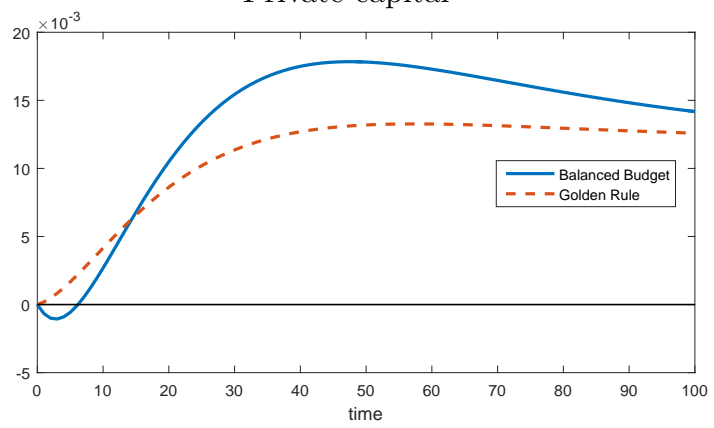

Consumption

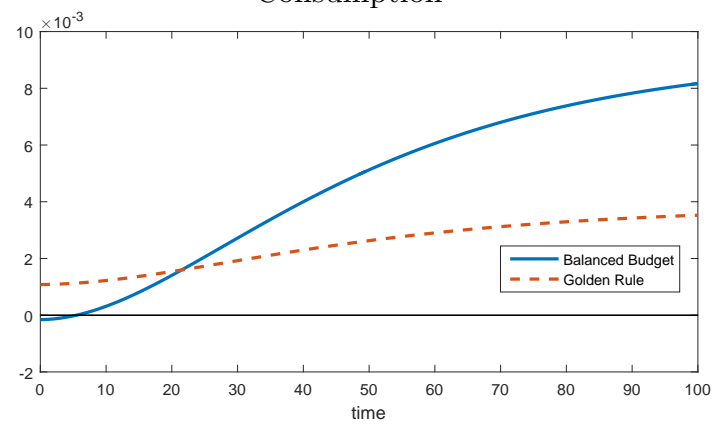


Figure 3: Intergenerational Welfare Effects of a Permanent Public Investment Impulse

Panel (a): Current generations $(v \leq 0)$

Total welfare change

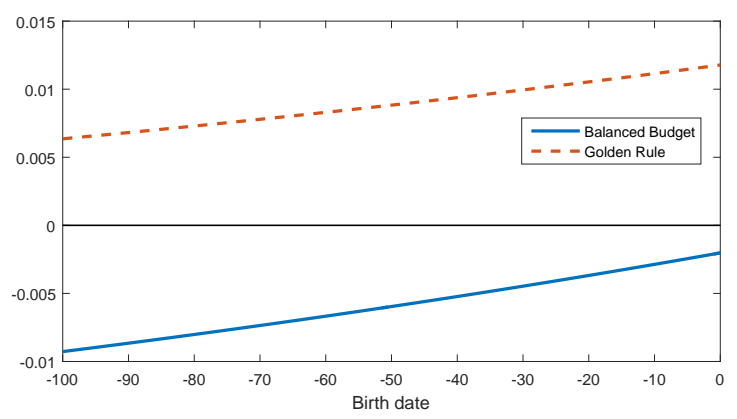

Human wealth effect

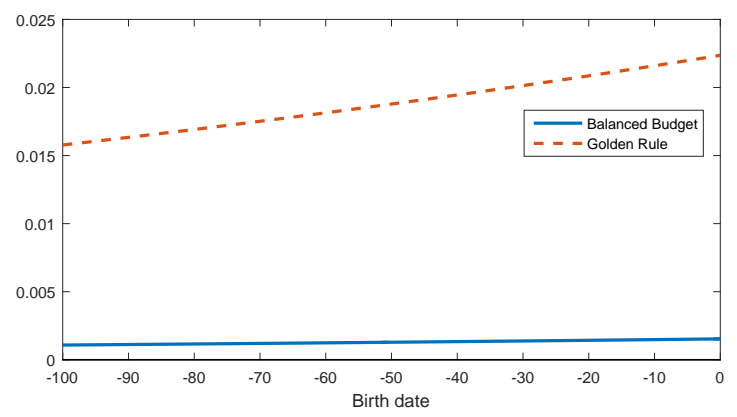

Financial wealth effect

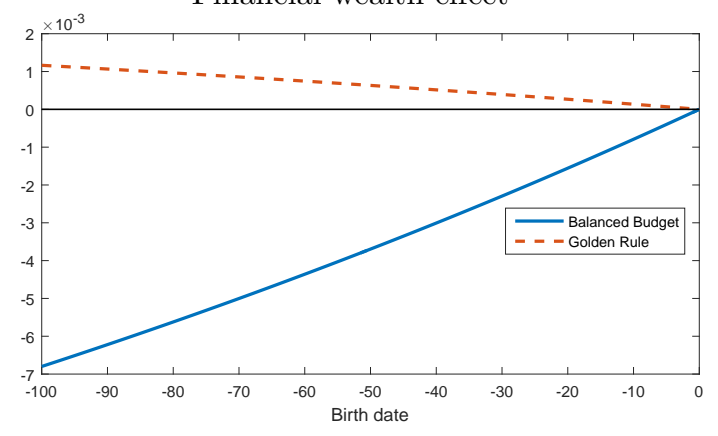

Panel (b): Future generations $(v>0)$

Total welfare change

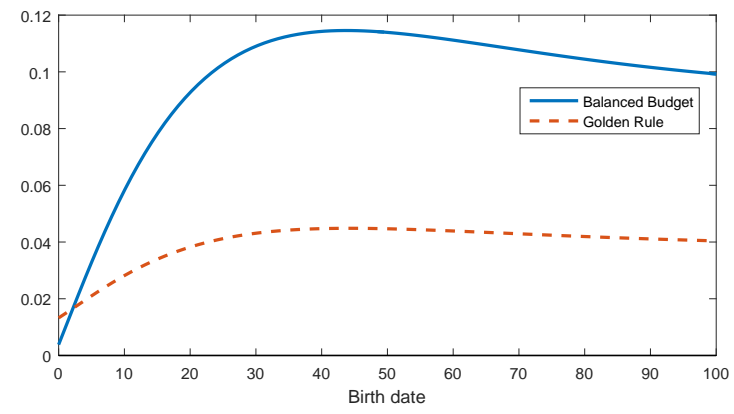

Human wealth effect

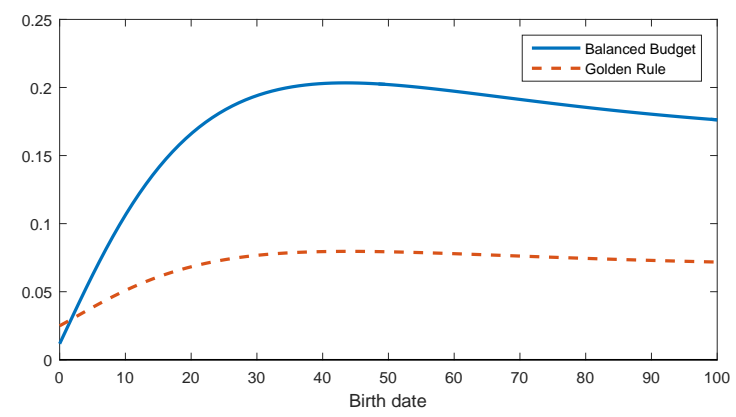

Notes: The total welfare change is the sum of the the human wealth effect, the financial wealth effect (which is absent for future generations), and the price level effect (not shown); see equations (27) and (28). 
Figure 4: Welfare Effects on Current Generations: Alternative Values of $\omega_{L L}$

Panel (a): $\omega_{L L}=0.5$

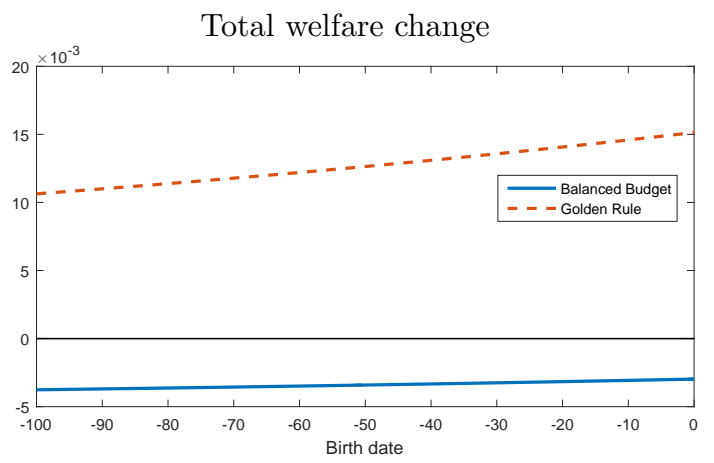

Human wealth effect

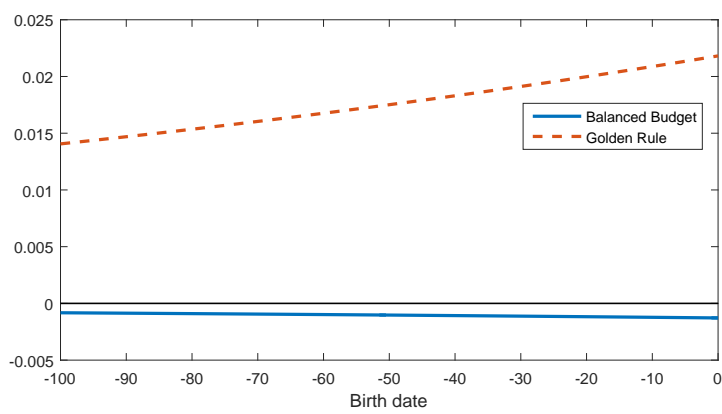

Financial wealth effect

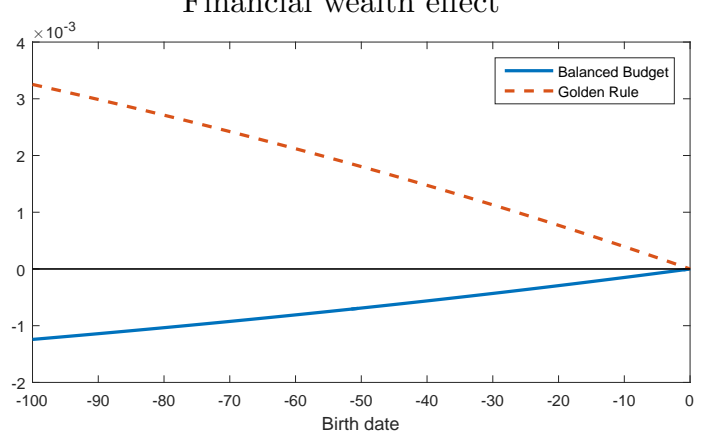

Panel (b): $\omega_{L L}=1.5$

Total welfare change

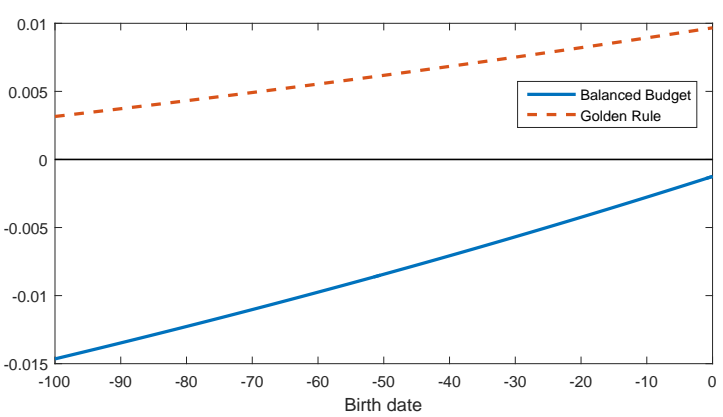

Human wealth effect

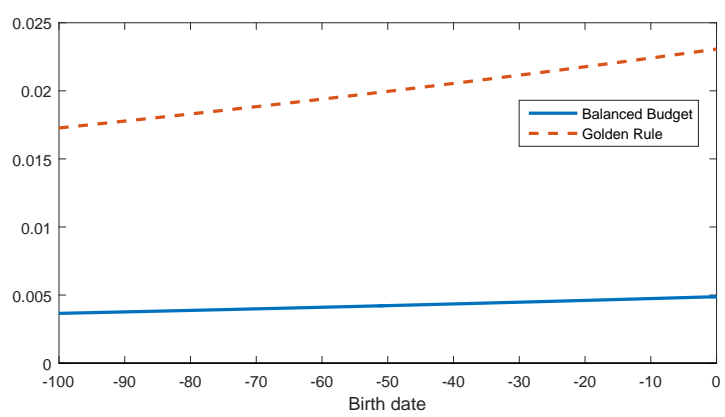

Financial wealth effect

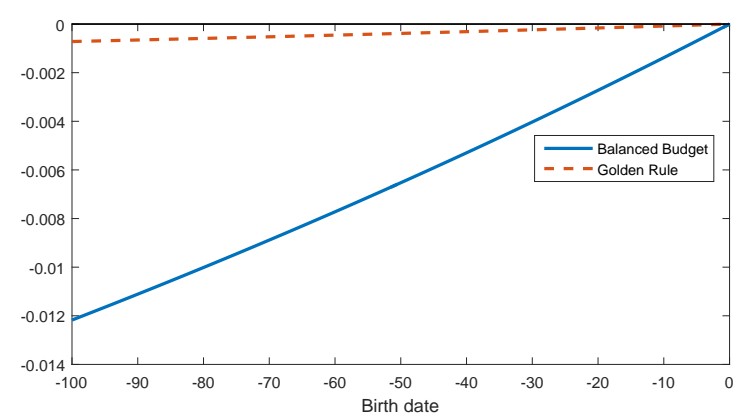

Notes: The total welfare change is the sum of the the human wealth effect, the financial wealth effect, and the price level effect (not shown); see equation (27). 
Figure 5: Welfare Effects on Current Generations: Alternative Values of $\eta$

Panel (a): $\eta=0.05$

Total welfare change

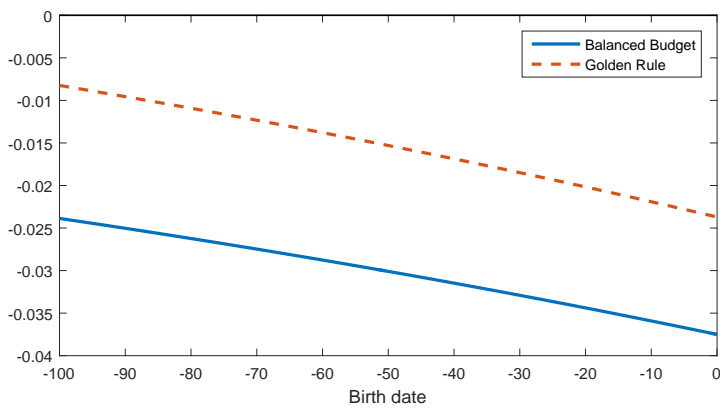

Human wealth effect

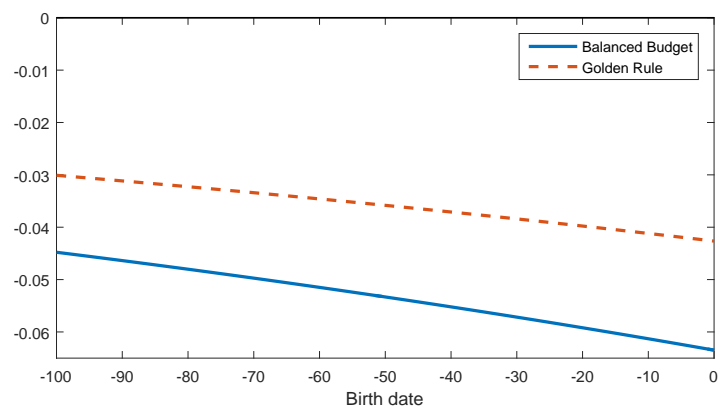

Financial wealth effect

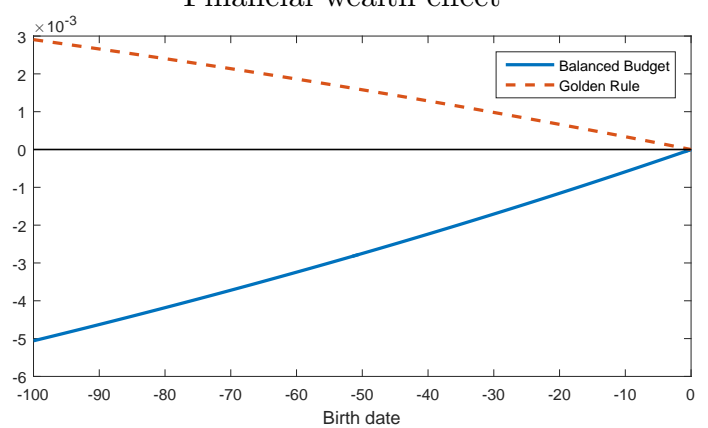

Panel (b): $\eta=0.10$

Total welfare change

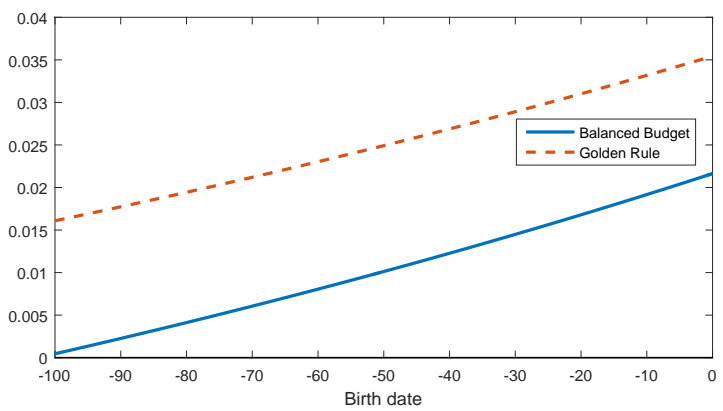

Human wealth effect

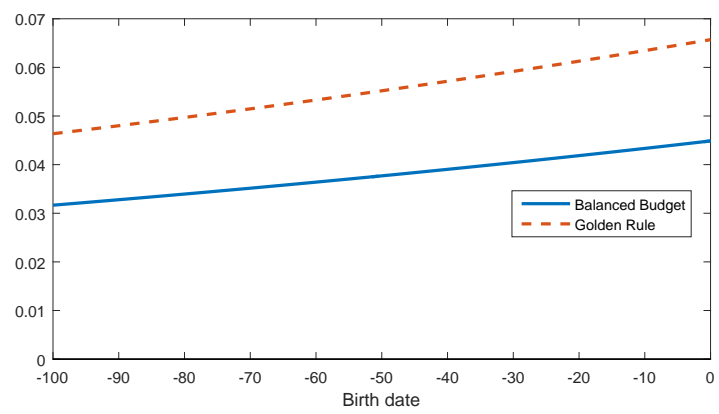

Financial wealth effect

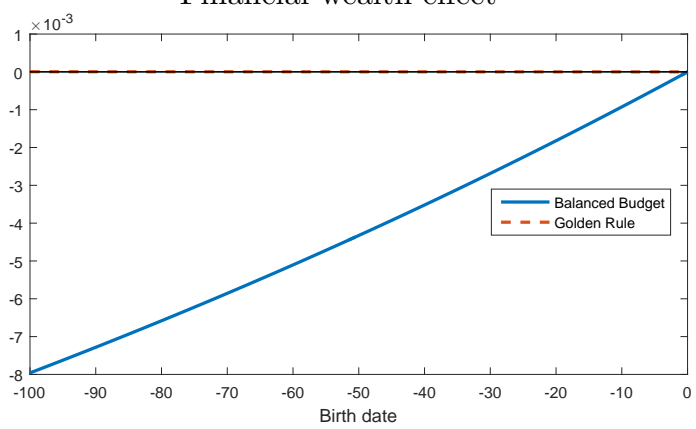

Notes: The total welfare change is the sum of the the human wealth effect, the financial wealth effect, and the price level effect (not shown); see equation (27). 
Table 1: Benchmark Parameter Values

\begin{tabular}{lll}
\hline \hline Description & Parameter/Share & Value \\
\hline Chosen values & & \\
Private consumption-to-GDP ratio & $C / Y$ & 0.560 \\
Government consumption-to-GDP ratio & $C_{G} / Y$ & 0.170 \\
Public investment-to-GDP ratio & $I_{G} / Y$ & 0.040 \\
Parameter of the capital installation function & $\kappa$ & 0.532 \\
Depreciation rate of private capital & $\delta$ & 0.100 \\
Rate of interest & $r$ & 0.040 \\
Public capital-to-GDP ratio & $K_{G} / Y$ & 0.580 \\
Public debt-to-GDP ratio & $B / Y$ & 0.580 \\
Leisure-labor ratio & $(1-L) / L$ & 1.000 \\
Birth/death rate & $\beta$ & 0.018 \\
Output elasticity of public capital & $\eta$ & 0.080 \\
Implied values & & \\
Private investment-to-GDP ratio & $I / Y$ & 0.230 \\
Output elasticity of private capital & $\varepsilon_{Y}$ & 0.331 \\
Depreciation rate of public capital & $\delta_{G}$ & 0.065 \\
Pure rate of time preference & $\alpha$ & 0.037 \\
Preference weight of consumption in utility & $\varepsilon_{C}$ & 0.562 \\
\hline \hline
\end{tabular}




\section{Appendix}

This appendix provides extra details on the structure and solution of the model. Complete derivations of the analytical results in this paper are reported in the Technical Appendix to this paper (see Bom, 2016).

\section{A.1 Log-Linearization}

I log-linearize the model around a steady state with $F=0$ and $B=K_{G}$. For a generic variable $x(t)$, I used the notational conventions $\tilde{x}(t) \equiv d x(t) / x$ and $\dot{\tilde{x}}(t) \equiv d \dot{x}(t) / x$, where $x$ is the steady-state value of $x(t)$. A few asset-like variables (namely, $H(t), F(t), B(t)$ and $A(t))$ are defined as $\tilde{x}(t) \equiv r d x(t) / Y$ and $\dot{\tilde{x}}(t) \equiv r d \dot{x}(t) / Y$. For the labor tax rate, I use $\tilde{t}_{L}(t) \equiv d t_{L}(t) /\left(1-t_{L}\right)$.

The dynamic equations of the model are log-linearized as follows:

$$
\begin{aligned}
& \dot{\tilde{K}}(t)=\frac{r \omega_{I}}{\omega_{K}}[\tilde{I}(t)-\tilde{K}(t)], \\
& \dot{\tilde{q}}(t)=r \tilde{q}(t)-\frac{r \varepsilon_{Y}}{\omega_{K}}[\tilde{Y}(t)-\tilde{K}(t)], \\
& \dot{\tilde{X}}(t)=(r-\alpha)\left[\tilde{X}(t)-\frac{\tilde{A}(t)}{\omega_{A}}\right], \\
& \dot{\tilde{A}}(t)=r\left[\tilde{A}(t)+\omega_{\bar{w}} \tilde{\bar{w}}(t)-\omega_{X} \tilde{X}(t)\right], \\
& \dot{\tilde{K}}_{G}(t)=\chi_{G}\left[\tilde{I}_{G}-\tilde{K}_{G}(t)\right],
\end{aligned}
$$

where $\omega_{I} \equiv I / Y, \omega_{K} \equiv r q K / Y, \omega_{A}=r A / Y, \omega_{\bar{w}} \equiv \bar{w} / Y, \omega_{X} \equiv X / Y$, and $\chi_{G} \equiv x \Phi_{G}^{\prime}(x)$.

Similarly, the log-linearized versions of the static equations are:

$$
\begin{aligned}
\tilde{q}(t) & =\rho_{A}[\tilde{I}(t)-\tilde{K}(t)], \\
\tilde{w}(t) & =\tilde{Y}(t)-\tilde{L}(t), \\
\tilde{Y}(t) & =\varepsilon_{Y} \tilde{K}(t)+\left(1-\varepsilon_{Y}\right) \tilde{L}(t)+\eta \tilde{K}_{G}(t), \\
\tilde{L}(t) & =\omega_{L L}[\tilde{\bar{w}}(t)-\tilde{X}(t)] \\
\tilde{C}(t) & =\tilde{X}(t), \\
\tilde{F}(t) & =\tilde{A}(t)-\omega_{K}[\tilde{q}(t)+\tilde{K}(t)]-\tilde{B}(t), \\
\tilde{P}(t) & =\left(1-\varepsilon_{C}\right) \tilde{\bar{w}}(t), \\
\tilde{\bar{w}}(t) & =\tilde{w}(t)-\tilde{t}_{L}(t),
\end{aligned}
$$


where I have further defined $\rho_{A} \equiv-x \Phi^{\prime}(x) / \Phi^{\prime \prime}(x)$ and $\omega_{L L}=(1-L) / L$.

Finally, the tax rate implied by the fiscal rules can be log-linearized and combined in a single equation as follows:

$$
\tilde{t}_{L}(t)=\frac{\left(\omega_{G}^{I}-d_{G} \chi_{G} \bar{y}_{G}\right) \tilde{I}_{G}+d_{G} \bar{y}_{G}\left(r+\chi_{G}\right) \tilde{K}_{G}(t)}{\left(1-\varepsilon_{Y}\right)\left(1-t_{L}\right)}-\bar{\theta}_{L}[\tilde{L}(t)+\tilde{w}(t)]
$$

where $d_{G}$ is an indicator variable assuming the values $d_{G}=1$ for the golden rule case and $d_{G}=0$ for the balanced-budget rule, $\omega_{G}^{I} \equiv I_{G} / Y, \bar{y}_{G} \equiv K_{G} / Y$, and $\bar{\theta}_{L} \equiv t_{L} /\left(1-t_{L}\right)$.

\section{A.2 Model Solution}

This section describes the solution of the log-linearized model. The model can be split into a static system and a dynamic system, which I discuss in turn.

\section{A.2.1 The Static System}

Equations (A.7)-(A.9), (A.13), and (A.14) can be combined and written in matrix form as

$$
\left[\begin{array}{ccc}
1 & -1 & -1 \\
1 & -1+\varepsilon_{Y} & 0 \\
0 & 1-\omega_{L L} \bar{\theta}_{L} & -\omega_{L L}\left(1+\bar{\theta}_{L}\right)
\end{array}\right]\left[\begin{array}{c}
\tilde{Y}(t) \\
\tilde{L}(t) \\
\tilde{w}(t)
\end{array}\right]=\left[\begin{array}{l}
0 \\
\tilde{K}^{*}(t) \\
Z^{*}(t)
\end{array}\right]
$$

where:

$$
\begin{aligned}
\tilde{K}^{*}(t) & \equiv \varepsilon_{Y} \tilde{K}(t)+\eta \tilde{K}_{G}(t), \\
Z^{*}(t) & \equiv-\frac{\omega_{L L}}{\left(1-\varepsilon_{Y}\right)\left(1-t_{L}\right)}\left[\left(\omega_{G}^{I}-d_{G} \chi_{G} \bar{y}_{G}\right) \tilde{I}_{G}+d_{G} \bar{y}_{G}\left(r+\chi_{G}\right) \tilde{K}_{G}(t)\right]-\omega_{L L} \tilde{X}(t) .
\end{aligned}
$$

Note that $\tilde{K}_{G}(t)=\left(1-e^{-\chi_{G} t}\right) \tilde{I}_{G}$ from solving (A.5).

Inverting the $3 \times 3$ matrix on the left-hand side of (A.15) gives the solution of the static system as follows:

$$
\left[\begin{array}{c}
\tilde{Y}(t) \\
\tilde{L}(t) \\
\tilde{w}(t)
\end{array}\right]=\frac{1}{1+\omega_{L L}\left[\varepsilon_{Y}\left(1+\bar{\theta}_{L}\right)-\bar{\theta}_{L}\right]}\left[\begin{array}{cccc}
\xi_{y k} & \xi_{y x} & \xi_{y g} & \xi_{y d} \\
\xi_{l k} & \xi_{l x} & \xi_{l g} & \xi_{l d} \\
\xi_{w k} & \xi_{w x} & \xi_{w g} & \xi_{w d}
\end{array}\right]\left[\begin{array}{l}
\tilde{K}(t) \\
\tilde{X}(t) \\
\left(1-e^{-\chi_{G} t}\right) \tilde{I}_{G} \\
\tilde{I}_{G}
\end{array}\right]
$$


where the $\xi_{i j}$ 's concerning output (first line) are defined as:

$$
\begin{array}{ll}
\xi_{y k} \equiv \varepsilon_{Y}\left(1+\bar{\omega}_{L L}\right), & \xi_{y x} \equiv-\left(1-\varepsilon_{Y}\right) \omega_{L L}, \\
\xi_{y g} \equiv \eta\left(1+\omega_{L L}\right)-d_{G} \omega_{L L}\left(1+\bar{\theta}_{L}\right) \bar{y}_{G}\left(r+\chi_{G}\right), & \xi_{y d} \equiv-\omega_{L L}\left(1+\bar{\theta}_{L}\right)\left(\omega_{G}^{I}-d_{G} \chi_{G} \bar{y}_{G}\right) .
\end{array}
$$

The coefficients for labor are:

$$
\begin{array}{ll}
\xi_{l k} \equiv \varepsilon_{Y} \omega_{L L}\left(1+\bar{\theta}_{L}\right), & \xi_{l x} \equiv-\omega_{L L}, \\
\xi_{l g} \equiv \omega_{L L}\left(1+\bar{\theta}_{L}\right) \eta-\frac{d_{G} \omega_{L L}\left(1+\bar{\theta}_{L}\right) \bar{y}_{G}\left(r+\chi_{G}\right)}{1-\varepsilon_{Y}}, & \xi_{l d} \equiv-\omega_{L L}\left(1+\bar{\theta}_{L}\right)\left(\omega_{G}^{I}-d_{G} \chi_{G} \bar{y}_{G}\right) .
\end{array}
$$

Finally, the coefficients for the wage rate are:

$$
\begin{array}{ll}
\xi_{w k} \equiv \varepsilon_{Y}\left(1-\omega_{L L} \bar{\theta}_{L}\right), & \xi_{w x} \equiv \omega_{L L} \varepsilon_{Y}, \\
\xi_{w g} \equiv\left(1-\omega_{L L} \bar{\theta}_{L}\right) \eta+\frac{d_{G} \varepsilon_{Y} \omega_{L L}\left(1+\bar{\theta}_{L}\right) \bar{y}_{G}\left(r+\chi_{G}\right)}{1-\varepsilon_{Y}}, & \xi_{w d} \equiv \frac{\varepsilon_{Y}}{1-\varepsilon_{Y}}\left[\omega_{L L}\left(1+\bar{\theta}_{L}\right)\left(\omega_{G}^{I}-d_{G} \chi_{G} \bar{y}_{G}\right)\right] .
\end{array}
$$

Using (A.13), (A.14) and the quasi-solution (A.16), the time path for after-tax wages is given by

$$
\tilde{\bar{w}}(t)=\xi_{\bar{w} k} \tilde{K}(t)+\xi_{\bar{w} x} \tilde{X}(t)+\xi_{\bar{w} g}\left(1-e^{-\chi_{G} t}\right) \tilde{I}_{G}+\xi_{\bar{w} d} \tilde{I}_{G},
$$

where the coefficients are:

$$
\begin{array}{ll}
\xi_{\bar{w} k} \equiv \xi_{w k}+\bar{\theta}_{L}\left(\xi_{l k}+\xi_{w k}\right), & \xi_{\bar{w} x} \equiv \xi_{w x}+\bar{\theta}_{L}\left(\xi_{l x}+\xi_{w x}\right), \\
\xi_{\bar{w} g} \equiv \xi_{w g}+\bar{\theta}_{L}\left(\xi_{l g}+\xi_{w g}\right)-\frac{d_{G}\left(1+\bar{\theta}_{L}\right) \bar{y}_{G}\left(r+\chi_{G}\right)}{1-\varepsilon_{Y}}, & \xi_{\bar{w} d} \equiv \xi_{w d}+\bar{\theta}_{L}\left(\xi_{l d}+\xi_{w d}\right)-\frac{\left(1+\bar{\theta}_{L}\right)\left(\omega_{G}^{I}-d_{G} \chi_{G} \bar{y}_{G}\right)}{1-\varepsilon_{Y}} .
\end{array}
$$

\section{A.2.2 The Dynamic System}

Equations (A.1)-(A.4) can be combined-while using (A.6) and the solutions for $\tilde{Y}(t)$ and $\tilde{\bar{w}}(t)$ in the first line of (A.16) and (A.17), respectively - to write the dynamic system in terms of one matrix equation of the form

$$
\left[\begin{array}{c}
\dot{\tilde{K}}(t) \\
\dot{\tilde{q}}(t) \\
\dot{\tilde{X}}(t) \\
\dot{\tilde{A}}(t)
\end{array}\right]=\underbrace{\left[\begin{array}{cccc}
\frac{r \omega_{I}}{\rho_{A} \omega_{K}} & 0 & 0 \\
\frac{r \varepsilon_{Y}}{\omega_{K}}\left(1-\xi_{y k}\right) & r & -\frac{r \varepsilon_{Y}}{\omega_{K}} \xi_{y x} & 0 \\
0 & 0 & r-\alpha & -\frac{r-\alpha}{\omega_{A}} \\
r \omega_{\bar{w}} \xi_{\bar{w} k} & 0 & r\left(\omega_{\bar{w}} \xi_{\bar{w} x}-\omega_{X}\right) & r
\end{array}\right]}_{\boldsymbol{\Delta}}\left[\begin{array}{c}
\tilde{K}(t) \\
\tilde{q}(t) \\
\tilde{X}(t) \\
\tilde{A}(t)
\end{array}\right]+\underbrace{\left[\begin{array}{c}
0 \\
\gamma_{q}(t) \\
0 \\
\gamma_{A}(t)
\end{array}\right]}_{\boldsymbol{\Gamma}(t)},
$$


where the shock terms are defined as:

$$
\begin{aligned}
\gamma_{q}(t) & \equiv-\frac{r \varepsilon_{Y}}{\omega_{K}}\left[\xi_{y g}\left(1-e^{-\chi_{G} t}\right) \tilde{I}_{G}+\xi_{y d} \tilde{I}_{G}\right], \\
\gamma_{A}(t) & \equiv r \omega_{\bar{w}}\left[\xi_{\bar{w} g}\left(1-e^{-\chi_{G} t}\right) \tilde{I}_{G}+\xi_{\bar{w} d} \tilde{I}_{G}\right] .
\end{aligned}
$$

For notational convenience, the shock terms can be written more compactly as follows:

$$
\gamma_{i}(t)=\pi_{i p}+\pi_{i t} e^{-\chi_{G} t}, \quad \text { for } i=q, A,
$$

where:

$$
\begin{aligned}
\pi_{q p} & \equiv \frac{r \varepsilon_{Y}}{\omega_{K}}\left[\left(\xi_{y g}+\xi_{y d} d_{D}\right) \tilde{I}_{G}+\xi_{y s} d_{S} \tilde{t}_{L}\right] \\
\pi_{q t} & \equiv-\frac{r \varepsilon_{Y} \xi_{y g}}{\omega_{K}} \tilde{I}_{G}, \\
\pi_{A p} & \equiv-r\left[\left(\omega_{\bar{w}} \xi_{\bar{w} g}+\omega_{\bar{w}} \xi_{\bar{w} d} d_{D}\right) \tilde{I}_{G}+\omega_{\bar{w}} \xi_{\bar{w} s} d_{S} \tilde{t}_{L}\right] \\
\pi_{A t} & \equiv r \omega_{\bar{w}} \xi_{\bar{w} g} \tilde{I}_{G} .
\end{aligned}
$$

The trace of $\boldsymbol{\Delta}$ is the sum of its diagonal elements: $\operatorname{tr}(\boldsymbol{\Delta})=3 \alpha-r>0$. Its determinant can be shown to be (see Bom, 2016):

$$
|\Delta|=(r-\alpha) \frac{r^{3} \omega_{I} \varepsilon_{Y}\left(1-\varepsilon_{Y}\right) \omega_{\bar{w}}}{\rho_{A} \omega_{K}^{2} \omega_{A}\left[1-\omega_{L L}\left(\bar{\theta}_{L}-\varepsilon_{Y}-\bar{\theta}_{L} \varepsilon_{Y}\right)\right]},
$$

which is strictly positive provided that $\omega_{L L}<1 /\left(\bar{\theta}_{L}-\varepsilon_{Y}-\bar{\theta}_{L} \varepsilon_{Y}\right)$ (i.e., for not too large elasticities of labor labor supply). In light of its positive trace, the positive determinant of $\Delta$ indicates either four positive or two positive and two negative characteristic roots. Plausible parameter values yield the latter case (see Section 4.1 in the main text).

\section{A.2.3 Impact Jumps}

Let $\delta_{i j}$ denote the typical element in the $i$-th row and $j$-th column of the Jacobian matrix $\Delta$. Also, define

$$
\phi(x) \equiv\left(x-\delta_{33}\right)\left(x-\delta_{32}\right)-\delta_{34} \delta_{43} .
$$


Then, the impact effects (immediately upon the shock, at $t=0$ ) on the jumping variablesi.e., Tobin's $q$ and full consumption - are given by

$$
\left[\begin{array}{c}
\tilde{q}(0) \\
\tilde{X}(0)
\end{array}\right]=\left[\begin{array}{ll}
\phi\left(r_{1}^{*}\right)+\delta_{23} \delta_{34} \omega_{K} & \delta_{23}\left(r_{1}^{*}-\delta_{22}\right) \\
\phi\left(r_{2}^{*}\right)+\delta_{23} \delta_{34} \omega_{K} & \delta_{23}\left(r_{2}^{*}-\delta_{22}\right)
\end{array}\right]^{-1}\left[\begin{array}{c}
\phi\left(r_{1}^{*}\right) \mathcal{L}\left\{\gamma_{q}, r_{1}^{*}\right\}+\delta_{23} \delta_{34} \mathcal{L}\left\{\gamma_{A}, r_{1}^{*}\right\} \\
\phi\left(r_{2}^{*}\right) \mathcal{L}\left\{\gamma_{q}, r_{2}^{*}\right\}+\delta_{23} \delta_{34} \mathcal{L}\left\{\gamma_{A}, r_{2}^{*}\right\}
\end{array}\right]
$$

where $r_{1}^{*}$ and $r_{2}^{*}$ denote the positive (unstable) eigenvalues of $\boldsymbol{\Delta}$, and

$$
\mathcal{L}\left\{\gamma_{i}, r_{j}^{*}\right\} \equiv \int_{0}^{\infty} \gamma_{i}(t) e^{-r_{j}^{*} t} d t, \quad \text { for } i=q, A \quad \text { and } j=1,2
$$

denotes the Laplace transform of $\gamma_{i}(t)$ using $r_{j}^{*}$ as the discount rate.

\section{A.2.4 Impulse Responses}

Solving the dynamic system (A.18) amounts to finding the reduced-form impulse response functions for the state variables as a function of the public investment shock. Denote the negative (stable) roots by $h_{1}^{*}$ and $h_{2}^{*}$ and define the following temporary transition and permanent adjustment terms:

$$
\begin{aligned}
\mathbf{T}_{\mathbf{1}}\left(h_{1}^{*}, h_{2}^{*}, t\right) & \equiv \frac{e^{h_{1}^{*} t}-e^{h_{2}^{*} t}}{h_{1}^{*}-h_{2}^{*}}, \\
\mathbf{T}_{\mathbf{2}}\left(h_{1}^{*}, h_{2}^{*}, t\right) & \equiv \frac{h_{1}^{*} e^{h_{1}^{*} t}-h_{2}^{*} e^{h_{2}^{*} t}}{h_{1}^{*}-h_{2}^{*}}=\frac{d \mathbf{T}_{\mathbf{1}}\left(h_{1}^{*}, h_{2}^{*}, t\right)}{d t}, \\
\mathbf{T}_{\mathbf{3}}\left(h_{1}^{*}, h_{2}^{*}, \chi_{G}, t\right) & \equiv \frac{1}{h_{1}^{*}-h_{2}^{*}}\left(\frac{e^{h_{1}^{*} t}-e^{-\chi_{G} t}}{h_{1}^{*}+\chi_{G}}-\frac{e^{h_{2}^{*} t}-e^{-\chi_{G} t}}{h_{2}^{*}+\chi_{G}}\right), \\
\mathbf{A}\left(h_{1}^{*}, h_{2}^{*}, t\right) & \equiv \frac{1}{h_{1}^{*}-h_{2}^{*}}\left(\frac{e^{h_{1}^{*} t}-1}{h_{1}^{*}}-\frac{e^{h_{2}^{*} t}-1}{h_{2}^{*}}\right)=\mathbf{T}_{\mathbf{3}}\left(h_{1}^{*}, h_{2}^{*}, 0, t\right) .
\end{aligned}
$$

As shown in the Technical Appendix to this paper (Bom, 2016), the reduced-form impulse response functions of the state variables are then given $b^{7}$

$$
\left[\begin{array}{c}
\tilde{K}(t) \\
\tilde{q}(t) \\
\tilde{X}(t) \\
\tilde{A}(t)
\end{array}\right]=\left[\begin{array}{cccc}
\delta_{12} \tilde{q}(0) & 0 & \vartheta_{13} & \vartheta_{14} \\
\vartheta_{21} & \tilde{q}(0) & \vartheta_{23} & 0 \\
\vartheta_{31} & \tilde{X}(0) & \vartheta_{33} & \vartheta_{34} \\
\vartheta_{41} & \omega_{K} \tilde{q}(0) & \vartheta_{43} & \vartheta_{44}
\end{array}\right]\left[\begin{array}{c}
\mathbf{T}_{\mathbf{1}}\left(h_{1}^{*}, h_{2}^{*}, t\right) \\
\mathbf{T}_{\mathbf{2}}\left(h_{1}^{*}, h_{2}^{*}, t\right) \\
\mathbf{T}_{\mathbf{3}}\left(h_{1}^{*}, h_{2}^{*}, \chi_{G}, t\right) \\
\mathbf{A}\left(h_{1}^{*}, h_{2}^{*}, t\right)
\end{array}\right]
$$

\footnotetext{
${ }^{7}$ This is true for real-valued characteristic roots. As detailed in the Technical Appendix, the transitions terms need to be modified if roots turn out to be complex (see Bom, 2016).
} 
where the remaining $\vartheta_{i j}$ 's concerning $\tilde{K}(t)$ (first row) are:

$$
\vartheta_{13}=-\delta_{12} \frac{\pi_{q t} \phi\left(-\chi_{G}\right)+\pi_{A t} \delta_{23} \delta_{34}}{\left(r_{1}^{*}+\chi_{G}\right)\left(r_{2}^{*}+\chi_{G}\right)}, \quad \vartheta_{14}=\delta_{12} \frac{\pi_{q p}\left(\delta_{34} \delta_{43}-\delta_{22} \delta_{33}\right)-\pi_{A p} \delta_{23} \delta_{34}}{r_{1}^{*} r_{2}^{*}}
$$

Concerning $\tilde{q}(t)$ (second row), the terms $\vartheta_{21}$ and $\vartheta_{23}$ are given by:

$$
\begin{aligned}
& \vartheta_{21}=\left(r_{1}^{*}+r_{2}^{*}-\delta_{22}-\delta_{33}\right) \tilde{q}(0)+\delta_{23} \tilde{X}(0)-\left(\pi_{q p}+\pi_{q t}\right), \\
& \vartheta_{23}=\frac{\chi_{G}\left[\pi_{q t} \phi\left(-\chi_{G}\right)+\delta_{23} \delta_{34} \pi_{A t}\right]}{\left(r_{1}^{*}+\chi_{G}\right)\left(r_{2}^{*}+\chi_{G}\right)} .
\end{aligned}
$$

For $\tilde{X}(t)$ (third row), the $\vartheta_{i j}$ 's are:

$$
\begin{aligned}
& \vartheta_{31}=\delta_{34} \omega_{K} \tilde{q}(0)+\left(r_{1}^{*}+r_{2}^{*}-2 \delta_{22}\right) \tilde{X}(0), \\
& \vartheta_{33}=-\frac{\delta_{34}\left(\delta_{12} \delta_{41} \pi_{q t}+\psi\left(-\chi_{G}\right) \pi_{A t}\right)}{\left(r_{1}^{*}+\chi_{G}\right)\left(r_{2}^{*}+\chi_{G}\right)}, \quad \vartheta_{34}=\frac{\delta_{12} \delta_{34}\left(\delta_{21} \pi_{A p}-\delta_{41} \pi_{q p}\right)}{r_{1}^{*} r_{2}^{*}} .
\end{aligned}
$$

Finally, the elements in the last row are given by:

$$
\begin{aligned}
& \vartheta_{41}=\omega_{K}\left(r_{1}^{*}+r_{2}^{*}-\delta_{22}-\delta_{33}\right) \tilde{q}(0)+\delta_{43} \tilde{X}(0)-\left(\pi_{A p}+\pi_{A t}\right), \\
& \vartheta_{43}=\frac{\left(\chi_{G}+\delta_{33}\right)\left[\delta_{12} \delta_{41} \pi_{q t}+\psi\left(-\chi_{G}\right) \pi_{A t}\right]}{\left(r_{1}^{*}+\chi_{G}\right)\left(r_{2}^{*}+\chi_{G}\right)}, \quad \vartheta_{44}=\frac{\delta_{12} \delta_{33}\left(\delta_{41} \pi_{q p}-\delta_{21} \pi_{A p}\right)}{r_{1}^{*} r_{2}^{*}} .
\end{aligned}
$$

The impulse responses for $\tilde{Y}(t), \tilde{L}(t)$, and $\tilde{w}(t)$ follow from using the solutions for $\tilde{K}(t)$ and $\tilde{X}(t)$ in (A.16). The impulse responses for the remaining variables can be straightforwardly obtained by using the corresponding equations in Section A.1. 


\section{References}

Bassetto, M. And T. J. Sargent (2006): "Politics and Efficiency of Separating Capital and Ordinary Government Budgets," Quarterly Journal of Economics, 121, $1167-1210$.

Baxter, M. And R. G. KIng (1993): "Fiscal Policy in General Equilibrium," American Economic Review, 83, 315-334.

Blanchard, O. J. (1985): "Debt, Deficits, and Finite Horizons," Journal of Political Economy, 93, 223-247.

Blanchard, O. J. And F. Giavazzi (2004): "Improving the SGP through a Proper Accounting of Public Investment," CEPR Discussion Paper No 4220, Centre for Economic Policy Research.

Bom, P. R. (2016): "Fiscal Rules and the Intergenerational Welfare Effects of Public Investment: Technical Appendix," University of Deusto.

Bom, P. R. And J. E. Ligthart (2014a): "Public Infrastructure Investment, Output Dynamics, and Balanced Budget Fiscal Rules," Journal of Economic Dynamics and Control, 40, 334-354.

(2014b): "What Have We Learned from Three Decades of Research on the Productivity of Public Capital?" Journal of Economic Surveys, 28, 889-916.

Creel, J., P. Hubert, and F. Saraceno (2013): "An Assessment of the Stability and Growth Pact Reform in a Small-Scale Macro-Framework," Journal of Economic Dynamics and Control, 37, 1567-1580.

DrautzBurg, T. And H. Uhlig (2015): "Fiscal Stimulus and Distortionary Taxation," Review of Economic Dynamics, 18, 894-920.

Groneck, M. (2010): “A Golden Rule of Public Finance or a Fixed Deficit Regime?" Economic Modelling, 27, 523-534.

Guo, J.-T. And S. G. Harrison (2008): "Useful Government Spending and Macroeconomic (In)Stability under Balanced-Budget Rules," Journal of Public Economic Theory, 10, 383-397. 
Heijdra, B. J. And L. Meijdam (2002): "Public Investment and Intergenerational Distribution," Journal of Economic Dynamics and Control, 26, 707-735.

IMF (2014): World Economic Outlook: Legacies, Clouds, Uncertainties, Washington: International Monetary Fund.

Leeper, E. M., T. B. Walker, And S.-C. S. Yang (2010): "Government Invesment and Fiscal Stimulus," Journal of Monetary Economics, 57, 1000-1012.

Menguy, S. (2015): "Advantages of Following a Golden Rule in a Monetary Union," Macroeconomic Dynamics, 1-28.

Minea, A. And P. Villieu (2009): "Borrowing to Finance Public Investment? The 'Golden Rule of Public Finance Reconsidered in an Endogenous Growth Setting," Fiscal Studies, 30, 103-133.

OECD (2012): Strategic Transport Infrastructure Needs to 2030, Paris: OECD Publishing.

Schaechter, A., T. Kinda, N. Budina, And A. Weber (2013): "Fiscal Rules in Response to the Crisis - Toward the "Next-Generation" Rules. A New Dataset," IMF Working Paper WP/12/187, International Monetary Fund.

Schmitt-Grohé, S. And M. Uribe (1997): "Balanced-Budget Rules, Distortionary Taxes, and Aggregate Instability," Journal of Political Economy, 105, 976-1000.

Turnovsky, S. J. And W. H. Fisher (1995): "The Composition of Government Expenditure and Its Consequences for Macroeconomic Performance," Journal of Economic Dynamics and Control, 19, 747-786.

Xue, J. AND C. K. YIP (2015): "Balanced-Budget Rules, Elasticity of Substitution, and Macroeconomic (In)Stability," Journal of Public Economic Theory, 17, 196-218.

YAARI, M. E. (1965): "Uncertain Lifetime, Life Insurance, and the Theory of the Consumer," Review of Economic Studies, 32, 137-150. 